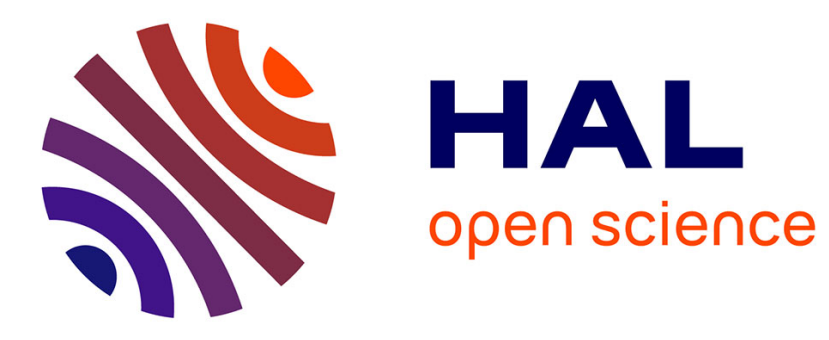

\title{
5' Triphosphorylated Small Interfering RNAs Control Replication of Hepatitis B Virus and Induce an Interferon Response in Human Liver Cells and Mice
}

Gregor Ebert, Hendrik Poeck, Julie Lucifora, Nikola Baschuk, Knud Esser, Irene Esposito, Gunther Hartmann, Ulrike Protzer

\section{To cite this version:}

Gregor Ebert, Hendrik Poeck, Julie Lucifora, Nikola Baschuk, Knud Esser, et al.. 5' Triphosphorylated Small Interfering RNAs Control Replication of Hepatitis B Virus and Induce an Interferon Response in Human Liver Cells and Mice. Gastroenterology, 2011, 141 (2), pp.696-706.e3. 10.1053/j.gastro.2011.05.001 . hal-03315628

\author{
HAL Id: hal-03315628 \\ https://hal.science/hal-03315628
}

Submitted on 12 Aug 2021

HAL is a multi-disciplinary open access archive for the deposit and dissemination of scientific research documents, whether they are published or not. The documents may come from teaching and research institutions in France or abroad, or from public or private research centers.
L'archive ouverte pluridisciplinaire HAL, est destinée au dépôt et à la diffusion de documents scientifiques de niveau recherche, publiés ou non, émanant des établissements d'enseignement et de recherche français ou étrangers, des laboratoires publics ou privés. 


\section{5' Triphosphated Small Interfering RNAs Control Replication of Hepatitis B Virus and Induce an Interferon Response in Human Liver Cells and Mice}

Gregor Ebert ${ }^{1}$, Hendrik Poeck ${ }^{2}$, Julie Lucifora ${ }^{1}$, Nikola Baschuk $^{3}$, Knud Esser $^{1}$, Irene Esposito $^{4}$, Gunther Hartmann ${ }^{5}$ and Ulrike Protzer ${ }^{1}$

1 Institute of Virology, Technische Universität München / Helmholtz Zentrum München, Munich, Germany

2 Department of Internal Medicine III, University Hospital, Technische Universität München, Munich, Germany

3 Institute for Medical Microbiology, Immunology und Hygiene, University Hospital and Center for

Molecular Medicine Cologne (CMMC), Cologne, Germany

4 Institute of Pathology, Technische Universität München / Helmholtz Zentrum München, Munich, Germany

5 Institute of Clinical Chemistry and Clinical Pharmacology, University Hospital, University of Bonn, Bonn, Germany

Short title: 5' triphosphated siRNA control HBV

Corresponding Author:

Prof. Ulrike Protzer, MD

Institute of Virology

Technische Universität München / Helmholtz Zentrum München

Trogerstrasse 30, 81675 Munich

Germany

Phone: +49-89-4140-6821, Fax: +49-89-4140-6823

9 E-mail: protzer@tum.de

Conflict of interest: The authors have no conflict of interest. 
32 Funding sources: This study was supported by the Deutsche Forschungsgemeinschaft,

33 SFB 670 and SFB 576 to UP, SFB 670 and 704 to GH and BMBF GoBio to GH.

\section{Author involvement:}

35 GE acquired, analysed and interpreted the data; did statistical analysis; prepared figures

36 and text of the paper;

37 HP designed experiments, prepared reagents;

$38 \mathrm{JL}$ performed experiment for revision, analysed and interpreted data;

39 NB performed in vivo experiments;

40 IE performed histological staining and analysis;

41 KE technical and methodological support; preparation of cells;

$42 \mathrm{GH}$ participated in study concept and design and obtained funding;

43 UP concepted, designed and supervised the study; obtained funding; drafting and revision 44 of the manuscript;

45

Abbrevations: 3p-, triphosphate; 3p-RNA, 5'-triphosphated double stranded RNA; cccDNA, covalently closed circular DNA; ctrl-RNA, control-RNA; dsRNA, double-stranded RNA; HBV, hepatitis B virus; HBeAg, hepatitis B e antigen; HBsAg, hepatitis B surface

49 antigen; IFN, interferon; L-protein, HBV large surface protein; OAS, $2^{`}-5^{`}$-oligoadenylate 50 synthetase; PEI, polyethylenimine; pgRNA, pregenomic HBV RNA; poly:IC, polyriboinosinic 51 polyribocytidylic acid; rcDNA, relaxed circular DNA; RIG-I, retinoic acid-inducible protein I; 52 siRNA, small interfering RNA; ssDNA, single stranded DNA; TLR, Toll-like receptors 
- Ebert et al.: 5' triphosphated siRNA control HBV -

\section{Abstract:}

Background \& Aims: Approved therapies for chronic hepatitis B include systemic administration of interferon (IFN)- $\alpha$ and inhibitors of hepatitis B virus (HBV) reverse transcription. Systemic application of IFN- $\alpha$ is limited by side effects. Reverse transcriptase inhibitors effectively control HBV replication, but rarely eliminate the virus and can select drug-resistant variants. We aimed to develop an alternative therapeutic approach that combines gene silencing with induction of IFN in the liver.

Methods: To stimulate an immune response while inhibiting HBV activity, we designed three small inhibitory (si)RNAs that target highly conserved sequences and multiple HBV transcripts of all genotypes. A 5'-triphosphate $(3 p)$ was added to the siRNAs turning them into a ligand for the cytosolic helicase retinoic acid-inducible protein I (RIG-I), which becomes activated and induces expression of type-1 IFNs. Antiviral activity was investigated in cell lines that replicate HBV, in HBV-infected primary human hepatocytes, and in HBV transgenic mice.

Results: 3p-double-stranded RNA (3p-RNA) activated RIG-I, induced a strong type-I IFN response (expression of IFN- $\beta$ ) in liver cells and showed transient but strong antiviral activity. Bi-functional, HBV-specific, 3p-siRNAs controlled replication of HBV more efficiently and for longer periods of time than 3p-RNAs without silencing capacity or siRNAs that targeted identical sequences but did not contain 3p.

Conclusions: HBV-specific 3p-siRNAs are bi-functional, antiviral molecules that induce production of type-I IFNs in the liver and target HBV RNAs to inhibit viral replication.

Keywords: virology, HBV infection, hepatitis B; gene silencing; interferon 


\section{Introduction}

About two billion people worldwide have been exposed to HBV, 350 million are chronically infected and 600000 die each year from consequences of hepatitis B. Approved therapies for chronic hepatitis B include interferon IFN- $\alpha$ and nucleos(t)ide analogues, which inhibit the viral reverse transcriptase and efficiently suppress HBV replication, but rarely lead to elimination of the virus ${ }^{1}$. HBV persists by establishing a nuclear transcription template, the so-called HBV covalently closed circular DNA (cccDNA) in hepatocytes, which is able to initiate a new HBV replication cycle even after serological clearance. Long-term therapy is required in the vast majority of cases bearing the risk of side effects and selection of drugresistant HBV mutants. Novel therapeutic approaches should at least induce sustained immune control of the virus and terminate chronic hepatitis B. To achieve this, combinatorial strategies targeting HBV from different angles will probably be necessary.

In infected cells, four major classes of mRNAs are transcribed. $3.5 \mathrm{~kb}$ pregenomic RNA is reverse transcribed into novel HBV genomes and serves as mRNA for translation of the viral core and polymerase proteins. A minimally longer RNA encodes the secretory HBeAg. 2.4 and $2.1 \mathrm{~kb}$ RNAs serve as mRNA for viral envelope proteins $\mathrm{L}, \mathrm{M}$ and $\mathrm{S}$. From the 0.7 kb RNA the HBV X protein is translated.

Organisms have evolved efficient host-defense mechanisms to sense viruses and block their replication and spread ${ }^{2}$. RNA interference based on cleavage of dsRNA into small interfering RNA (siRNA) by Dicer helicases is an important antiviral defense mechanism. Several siRNAs and small hairpin RNAs have already been shown to combat HBV ${ }^{3-6}$. Since all HBV RNAs share common 3' sequences, they may be targeted by a single siRNA. In addition, innate and adaptive immune responses are needed to overcome viral infection. Viral nucleic acids are recognized by specialized receptors ${ }^{2}$. The transmembrane Toll-like receptors $3,7,8$ and 9 detect viral RNA or DNA in the endosomal compartment of immune cells, whereas the cytoplasmic helicases RIG-I, melanoma differentiation-associated gene 5 and LGP2 are ubiquitous. 
- Ebert et al.: 5' triphosphated siRNA control HBV -

111 RIG-I detects viral RNA based on a 3p-present in panhandle structures of negative strand

112 RNA viruses 7,8 . RIG-I is effectively triggered by in vitro transcribed $3 p$-dsRNA

113 oligonucleotides ${ }^{7}$, which may be designed to serve as siRNAs with an additional

114 immunostimulatory function ${ }^{9,10}$. Antiviral responses triggered by RIG-I activation include

115 the induction of type-I IFN, inflammasome activation and proapoptotic signaling.

116 RIG-like and Dicer helicase families are phylogenetically related and offer the exciting new

117 therapeutic perspective to tackle two fundamental antiviral pathways for the treatment of

118 viral infection by a single molecule. In this project we developed a combinatorial, short

119 double-stranded RNA-based approach for the treatment of HBV infection, combining HBV

120 sequence specific gene silencing by RNA interference with RIG-I-induced antiviral activities.

121

122

123 
- Ebert et al.: 5' triphosphated siRNA control HBV -

124

125

126

127

128

129

130

131

132

133

134

135

136

137

138

139

140

141

142

143

144

145

146

147

148

149

150

151

152

\section{Material and Methods}

Generation of 3p-RNA and 3p-siRNA. HBV sequence specific siRNAs were designed to target sequences highly conserved among many HBV genotypes. Two target sequences within the common 3' end of all HBV RNA's were identified (targeted by si1.1 and si1.2) and one sequence within all except the X RNA (targeted by si1.3) (Fig. 3A). si1.1 targets all HBV genotypes A to F, si1.2 all except F and si1.3 targets genotypes A and D. Synthesized DNA oligonucleotide of sense and antisense strands (Table 1) were cloned into a suitable vector. The two 3pRNA strands were in vitro transcribed from these templates in separate reactions, purified by phenol:chloroform extraction after DNAse-I (Ambion, Huntington, UK) digestion of DNA templates, annealed overnight at $37^{\circ} \mathrm{C}$ and cleaned by Mini Quick Spin ${ }^{\mathrm{TM}}$ Oligo Columns (Roche, Mannheim, Germany) as previously described ${ }^{7,9}$. Chemically synthesized siRNAs and polyA RNA were purchased from Eurofins-MWG (Ebersberg, Germany) (Table 1). HCV-sequence specific siRNA ${ }^{6}$ served as control.

Cell culture. HepG2.2.15 cells are derived from human hepatoma HepG2 cells containing four copies of a 1.1-fold HBV genome, genotype A (adw). HepG2-H1.3 cells contain a single copy 1.3-fold overlength genotype D (ayw) HBV genome 11, 12. Primary human hepatocytes $(\mathrm{PHH})$ were isolated from surgical liver specimens of patients undergoing partial hepatectomy by a two-step collagenase perfusion and differential centrifugation at 50 $\mathrm{xg}$ as described ${ }^{13}$. Informed consent was obtained from each patient, and the procedure was approved by the local Ethics Committee. From supernatant of the $50 \mathrm{xg}$ centrifugation step, non-parenchymal liver cells were sedimented at $300 \mathrm{xg}$ and purified by an OptiPrep ${ }^{\mathrm{TM}}$ (Pierce, Rockford, USA) density gradient. Liver macrophages (Kupffer cells) were separated by plastic adherence step and cultured in RPMI medium (Invitrogen) containing $5 \%$ donor serum. Liver sinusoidal endothelial cells were purified by CD31 magnetic beads (Miltenyi, Bergisch Gladbach, Germany) and HEPES-buffered Williams Medium E (Invitrogen) containing 5\% donor serum. Three days after plating, $\mathrm{PHH}$ were infected with genotype A HBV concentrated from supernatant of HepG2.2.15 cells at a multiplicity of infection of 100 enveloped, DNA containing particles / cell. 
153 Transfection of RNA. HepG2-H1.3 cells were transfected in suspension before seeding in

154 12-well or 6-well plates. PHH were transfected adherent to 12 -well plates at day 4 after 155 HBV infection in triplicates. To remove the HBV inoculum, medium was exchanged at day 1 156 after transfection or infection, respectively. $0.5 \mu \mathrm{g} 3 p-R N A$, siRNA or control-RNA, 157 respectively, or $0.05 \mu \mathrm{g}$ of polyriboinosinic polyribocytidylic acid (poly (I:C)) mixed with $6 \mu \mathrm{l}$ 158 Hiperfect (Qiagen, Hilden, Germany) according to manufacturer`s instructions were added 159 per ml cell culture medium. As mock control, we used Hiperfect without RNA. To analyze 160 cell viability after transfection, $25 \mu$ XTT labeling mixture (XTT Cell Proliferation Kit II, 161 Roche) was added to $10^{4}$ cells, incubated for $2 \mathrm{~h}$ and absorbance was quantified using a 162 scanning multi-well spectrophotometer.

163 Treatment of HBV transgenic mice. HBV transgenic mice $(\sim 20 \mathrm{~g})$ of mouse strain HBV1.3

164 xfs ( ${ }^{14}$, HBV genotype D, kindly provided by $\mathrm{H}$. Schaller) were grouped by serum $\mathrm{HBeAg}$ 165 levels. Each mouse was i.v. injected twicely three days apart into the tail vein with $25 \mu \mathrm{g}$ 166 RNA complexed with in vivo-JetPEITM (Polyplus, New York, USA) according to the 167 manufacturer's instructions in a total volume of $200 \mu \mathrm{l} 5 \%$ glucose. As mock control we 168 used polyethylenimine (PEI) without RNA. Injection was repeated after three days and mice 169 were sacrificed six to 15 days after first injection. To determine serum IFN levels, mice were 170 bled retroorbitally, and IFN- $\alpha$ was measured by ELISA (Biosource, Solingen, Germany),

171 HBV assays. Cell culture medium was collected at indicated time points and analyzed for 172 HBsAg and $\mathrm{HBeAg}$ by commercially available immunoassays (Axsym ${ }^{\mathrm{TM}} ;$ Abbott, 173 Wiesbaden, Germany). HBV progeny levels were determined in $200 \mu \mathrm{l}$ of cell culture 174 medium or $50 \mu \mathrm{l}$ mouse serum by real time PCR using primer HBV1745 and HBV1844 $\left({ }^{15}\right.$, 175 Supplementary Table). Intracellular HBV replicative intermediates were analyzed by 176 Southern blot analysis of total HindIII digested DNA extracted by phenol-chloroform from 177 mouse liver tissue $(75 \mu \mathrm{g})$ or HepG2-H1.3 cells $(20 \mu \mathrm{g})$, respectively, after separation 178 through a $0.85 \%$ agarose gel. HBV RNA subspecies were analysed by Northern blotting of $17925 \mu \mathrm{g}$ total RNA from HepG2 H1.3 cells separated through a $1 \%$ agarose gel containing $18037 \%$ formaldehyd. For detection, ${ }^{32} \mathrm{P}$ labeled HBV DNA probes were used. 
- Ebert et al.: 5' triphosphated siRNA control HBV -

181 Analysis of gene expression and HBV pgRNA by RT-PCR. Total RNA from $10^{6}$ HepG2-

$182 \mathrm{H} 1.3$ cells was extracted using the RNeasy ${ }^{\circledR}$ total RNA extraction kit (Qiagen). Total RNA

183 from $2 \times 10^{6} \mathrm{PHH}$ and $20 \mathrm{mg}$ mouse liver were extracted using Trizol (Invitrogen). $1 \mu \mathrm{g}$ RNA

184 was reverse transcribed into cDNA (Superscript III cDNA synthesis kit, Invitrogen). For

185 gene expression analysis, exon-exon spanning primer pairs were selected (Supplementary

186 Table). Differential gene expression was quantified by real-time PCR relative to GAPDH

187 expression and normalized to a dilution series of calibrator cDNA using the DNA

188 Amplification SYBR Green Kit on a LightCycler ${ }^{\mathrm{TM}} 480$ II machine applying the Relative

189 Quantification Software (Roche).

190 5' ligase-mediated-RACE PCR. Total RNA isolated from $10^{6} \mathrm{HepG2-H1.3}$ cells was 191 dissolved in $40 \mu \mathrm{l}$ distilled water, heated to $65^{\circ} \mathrm{C}$ for 5 minutes and rapidly cooled on ice 192 before ligation to $250 \mathrm{ng}$ Gene Racer ${ }^{\mathrm{TM}} \mathrm{RNA}$ adaptor (Tab. 2) at $37^{\circ} \mathrm{C}$ for 1 hour in $50 \mu \mathrm{l}$ 193 10mM ATP, $80 \cup$ RNaseOut (Invitrogen), and $10 \cup$ RNA ligase (Ambion). After purification 194 using Amicon 100k filters (Millipore, Billerica, MA, USA), $10 \mu$ of the RNA ligation reaction 195 was reverse transcribed at $55^{\circ} \mathrm{C}$ using SuperScript III ${ }^{\mathrm{TM}}$ reverse transcriptase (Invitrogen) 196 and HBV-specific primer HBV 3081 rev hybridizing $3^{\prime}$ of the predicted si-1.2-mediated 197 mRNA cutting site. After inactivation at $70^{\circ} \mathrm{C}$ for 15 minutes RACE-PCR was performed 198 using forward primer GR5 fw binding the GeneRacer adaptor and reverse primer HBV 3075 $199 \operatorname{rev}\left(4^{\prime} 95^{\circ} \mathrm{C} ; 32\right.$ cycles: $30^{\prime \prime} 95^{\circ} \mathrm{C}, 20^{\prime \prime} 60^{\circ} \mathrm{C}, 6^{\prime \prime} 72^{\circ} \mathrm{C} ; 10^{\prime}$ at $\left.72^{\circ} \mathrm{C}\right)$. PCR products were 200 seperated through a 2\% TBE Agarose gel and visualized by ethidium bromide.

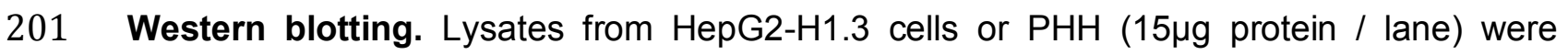
202 seperated by $12.5 \%$ SDS-PAGE. Proteins were transferred onto nitrocellulose membranes 203 and detected using anti-RIG-I monoclonal antibody (Alexis Biochemicals, Axxora, Lörrach, 204 Germany), anti-HBV-core antiserum H800 (kindly provided by H. Schaller) or anti-HBV-S 205 monoclonal antibody (Murex HBsAg Version 3 ELISA Kit, Abbott).

206 Histological analysis. Mouse livers slices were fixed in $10 \%$ buffered formalin and 207 embedded in paraffin. $8 \mu \mathrm{m}$ tissue sections were stained with HBV core protein specific 208 antibody (Diagnostic Biosystems, Pleasanton, CA, USA) or haematoxylin and eosin (H\&E). 209 Semiquantitative analysis of stained sections was performed by counting localization, 
210 intensity, distribution and percentage of positive cell staining (HBV-core) or the number of

211 focal lesions (hepatocyte necroses with inflammatory infiltrates, H\&E) throughout the whole

212 tissue specimen.

213 Statistical analysis. For statistical analysis, data were subjected to unpaired, two-tailed

214 Student's $t$-test and statistical significance was determined setting confidence intervals of $21595 \%$ using Prism 5.0a software.

Results

\section{5 -triphosphated RNA suppresses HBV replication.}

223 To test the antiviral potential of 3p-RNA in HBV infection, we transfected 3p-RNA (0.5 $\mu$ g / $224 \mathrm{ml}$ ) into HBV-infected PHH cultures (Fig. 1A). After transfection with 3p-RNA, but not with 225 the control polyA RNA, progeny HBV (Fig. 1A, left) as well as viral antigens $\mathrm{HBeAg}$ and $226 \mathrm{HBsAg}$ (Fig. 1A, middle) secreted into the cell culture medium were reduced by more than $22790 \%$ and comparable to the reduction observed after poly(I:C) treatment. Intracellular HBV $2283.5 \mathrm{~kb}$ RNA levels, decreased significantly (Fig. 1A, right). These effects were confirmed in 229 HepG2-H1.3 hepatoma cells (data not shown), an IFN-sensitive, stable cell line replicating 230 HBV ${ }^{11}$.

231 To test the antiviral effect of 3p-RNA in vivo, HBV transgenic mice were intravenously (i.v.) 232 injected with 3p-RNA or polyA RNA complexed with linear PEI or PEI only as control. HBV 233 transgenic mice replicate HBV from an integrated 1.3-fold overlength genome and secrete $234 \mathrm{HBV}$ into the bloodstream ${ }^{14,16}$. HBV viremia in 3p-RNA treated mice decreased about 1.6 $235 \log 6$ days after injection (Fig. 1B, left). In addition, serum HBeAg and HBsAg levels (Fig. 236 1B, middle) and intrahepatic HBV pgRNA (Fig. 1B, right) significantly dropped.

237 These results demonstrate that 3p-RNA exhibits antiviral activity against HBV in vitro and in 238 vivo. 
- Ebert et al.: 5' triphosphated siRNA control HBV -

239

240

241

242

243

244

245

246

247

248

249

250

251

252

253

254

\section{3p-RNA induces an interferon response in hepatocytes via activation of RIG-I.}

$3 p-R N A$ is well known to induce type-I IFN ${ }^{7,8,17}$, but may also induce apoptosis in tumor cells $^{9}$. To exclude apoptosis induction, a non-toxic concentration of 3p-RNA $(0.5 \mu \mathrm{g} / \mathrm{ml})$ as determined by cell viability test (Fig. 2A) - was used throughout our study.

To determine how 3p-RNA elicits its antiviral effects against HBV, we first checked whether it induces type-I IFN and IFN-induced 2'-5'-oligoadenylate synthetase (OAS). We transfected 3p-RNA into HepG2-H1.3 cells (Fig. 2B, left), HBV infected PHH (Fig. 2B, middle) and i.v. injected 3p-RNA into HBV tg mice (Fig. 2B, right). 3p-RNA treatment resulted in a rapid and potent, but transient type-I IFN response in vitro and in vivo. IFN- $\alpha$ level peaked after several hours in the serum of treated mice. IFN-induced 2'-5'-OAS expression was detected until day six after treatment (Fig. 2B)

Fig. $2 \mathrm{C}$ shows, that hepatoma HepG2-H1.3 cells as well as PHH constitutively express RIG-I. Stimulating IFN-response pathways by addition of recombinant IFN- $\alpha$ or by transfection with 3p-RNA upregulated RIG-I expression. To confirm that 3p-RNA activates IFN pathways via RIG-I in hepatocytes, we knocked down RIG-I expression by transfecting RIG-I specific siRNA resulting in a reduction of RIG-I until day 6 after transfection (Fig. 2D). Since the RIG-I knock-down was incomplete, it significantly, but incompletely antagonized IFN- $\beta$ induction after 3p-RNA stimulation in HepG2-H1.3 cells (Fig. 2E) and PHH (data not shown). As a consequence (and because RIG-I siRNA per se already had an effect), knocking down RIG-I only incompletely rescued HBV antigen secretion (Fig. 2F). This indicates that low levels of RIG-I are sufficient to induce the antiviral effect, but cannot completely exclude additional mediators.

\section{HBV specific 3p-siRNAs induce a potent interferon response and control HBV} replication in hepatocytes.

To enhance the therapeutic efficiency against HBV we intended to combine the immune stimulatory, antiviral effect of RIG-I stimulation with RNA interference mediated genesilencing effect. Therefore, we designed three HBV-sequence specific siRNAs (Table 1) each matching a panel of different HBV genotypes (for details see methods). siRNAs si-1.1 
268 and si-1.2 target all HBV RNAs, si-1.3 targets all except the X RNA (Fig. 3A). siRNAs

269 furnished with 5 -triphosphate groups by in vitro transcription were termed $3 p-1.1,3 p-1.2$ 270 and $3 p-1.3$

271 To determine whether $3 p$-siRNA is able to induce an antiviral IFN response, HepG2-H1.3

272 cells were transfected with HBV-specific 3p-siRNAs and corresponding non-phosphated 273 siRNAs. All three 5 -triphosphated HBV siRNAs designed (3p-1.1, 3p-1.2 and 3p-1.3) led to 274 comparable induction of IFN- $\beta$ gene expression (Supplementary Fig.1). Using primary 275 human liver cells, IFN- $\beta$ was induced by $3 p-1.2$ in $\mathrm{PHH}$ as well as in purified primary human 276 liver sinusoidal endothelial cells and liver macrophages, so called Kupffer cells 277 (Supplementary Fig. 2). As exemplarily shown for si1.2, 3p-siRNA but not non-phosphated 278 siRNA induced expression of IFN- $\beta$ (Fig. 3B). In addition, si-1.2 as well as $3 p-1.2$ clearly 279 functioned as siRNAs and induced cleavage of HBV RNAs - in contrast to control siRNA, 280 poly(I:C) and 3p-RNA (Fig. 3C). After transfection of 3p-1.1, 3p-1.2 or 3p-1.3 we observed a 281 significant reduction in HBV progeny as well as $\mathrm{HBeAg}$ and $\mathrm{HBsAg}$ levels released from 282 HBV replicating stable cell line HepG2-H1.3 (Fig. 3D). A comparable, strong antiviral effect 283 was achieved in HBV-infected PHH (Fig. 3E). Northern blot analysis revealed a comparable 284 effect of all three 3p-siRNAs on pre- and subgenomic HBV RNAs (Fig. 3F).

285 These data suggest that HBV specific 3p-siRNAs stimulate RIG-I, induce an IFN response 286 and control HBV replication and antigen secretion.

Superior anti-HBV activity of 3p-siRNAs combining RIG-I activation and gene silencing.

290 To analyze whether bi-functional 3p-siRNAs have a superior antiviral effect, we compared 291 the primarily used RIG-I ligand 3p-RNA to our newly designed HBV-sequence specific 3p292 siRNAs. Effects on HBV replication in HepG2-H1.3 cells were analyzed at day four and 293 eight after transfection by HBV DNA Southern blot (Fig. 4A). All HBV DNA replicative 294 intermediates were strongly reduced at day four after treatment with the original 3p-RNA and the HBV specific 3p-siRNAs. Intriguingly, 3p-siRNAs displayed a more pronounced and longer-lasting effect on HBV replication at day eight after transfection (Fig. 4A). 
- Ebert et al.: 5' triphosphated siRNA control HBV -

297 Corresponding to their gene silencing ability, all three 3p-siRNAs reduced expression levels

298 of the HBV envelope protein L emerging in a non-glycosylated and a glycosylated form and

299 the capsid protein core - with 3p-1.2 showing the strongest gene silencing effect. Non300 silencing 3p-RNA, in contrast had only a very minor effect at early time points after 301 transfection, which rapidly persisted (Fig. 4B). Due to the higher protein turn-over, the effect 302 on $L$ protein was more pronounced.

303 We next compared non-silencing 3p-RNA with the 3p-siRNAs and the respective non304 phosphated siRNAs. At day 8 post transfection, all three $3 p$-siRNAs proved at least as efficient in reducing HBV progeny release (Fig. 5A), HBeAg secretion (Fig. 5B), intracellular core protein expression (Fig. 5C) and HBV replication (Fig. 5D) as the respective siRNA and superior to non-silencing 3p-RNA.

308 Because the IFN-mediated antiviral effect appeared to be transient, we studied the antiviral 309 effect of si-1.2 and 3p-1.2 with non-silencing 3p-RNA and poly(l:C) in parallel over a time310 course of 16 days. Since HepG2-H1.3 cells start to transcribe HBV RNA only when they are 311 confluent ${ }^{18}$, HBV DNA levels reflecting progeny virus release (Fig. 5E) as well as $\mathrm{HBeAg}$ 312 levels (Fig. 5F) were low at day 0.5 and increased constantly until day 10 and 16, 313 respectively, in mock treated cells. 3p-RNA, si-1.2 and 3p-1.2 showed a pronounced 314 antiviral activity at early time points after transfection. The antiviral activity of $3 p-R N A$ and 315 poly (I:C), both eliciting their effect via transient activation of an IFN response, ceased first 316 and was comparable to mock treated cells again between day 8 and 10 (Fig. 5E,F). When 317 IFN levels were waning, a rebound effect was observed and HBV progeny production even 318 outnumbered that of mock controls (Fig. 5E). Only triphosphated siRNA 3p-1.2 and its nonphosphated counterpart si-1.2 reduced progeny HBV DNA over a longer time period, but 3p-1.2 was significantly more active from day 10 onwards in reducing HBV progeny release

321 (Fig. 5E) as well as HBeAg secretion (Fig. 5F).

322 Taken together, bi-functional 3p-siRNAs, which combine HBV gene silencing with immune323 stimulatory properties, display a superior antiviral activity on HBV and are able to repress 324 virus replication and antigen expression in vitro for more than two weeks. 
- Ebert et al.: 5' triphosphated siRNA control HBV -

\section{HBV specific 3p-siRNAs have a long lasting antiviral effect in vivo in HBV replicating} mice.

Finally, we wanted to compare 3p-RNA, 3p-siRNAs and corresponding siRNAs with respect to their antiviral activity in HBV transgenic mice in vivo. Complexed with PEI, 3p-RNA and 3p-siRNA serving as RIG-I ligands, but not non-phosphated siRNAs, triggered a rapid IFN$\alpha$ response 6 hours after intravenous injection (Fig. 6A).

To test the antiviral efficacy, HBV transgenic mice were grouped according to sex and HBeAg levels. Groups of five HBV transgenic mice each were treated with either $3 p-R N A$, HCV-specific control siRNA or HBV sequence specific siRNAs si-1.1 and si-1.2 or 3psiRNAs 3p-1.1 or 3p-1.2. To compare the effect on HBV replication, Southern blot analysis of HBV replicative forms in pooled liver DNA from each group of animals was performed (Fig. 6B). Consistent with our in vitro data, mice treated with 3p-RNA, siRNA and 3p-siRNA showed a clear reduction of intrahepatic HBV replication (Fig. 6B,C) and HBV pgRNA levels (Fig. 6D, left panel) in comparison to the control group at day 6 after treatment. Hereby, RIG-I ligand 3p-RNA and 3p-siRNAs proved superior to non-phosphated siRNAs. HBV core staining of liver tissue sections revealed a slight reduction in the number of core expressing mouse hepatocytes in si-1.2 treated and a marked reduction in 3p-RNA and 3p-siRNA treated animals (Fig. 6E), but also a reduction of cytoplasmic core staining indicating active virus replication. At day 9 after treatment, however, only the bi-functional $3 p-s i R N A$ still showed significant antiviral activity whereas the effects of $3 p-R N A$ and siRNA were not significant anymore (Fig. 6D. right panel).

A mild to moderate inflammatory activity was observed in livers of mice treated with $3 p-$ RNA and 3p-1.2, but not with siRNA indicating that IFN causes the inflammatory reaction (Fig. 6E).

These in vivo results confirmed our conclusion from the in vitro experiments, that the bifunctional HBV-specific 3p-siRNA is a potent and promising antiviral superior to its monofunctional analogues. 
- Ebert et al.: 5' triphosphated siRNA control HBV -

355

356

357

358

359

360

361

362

363

364

365

366

367

368

369

370

371

372

373

374

375

376

377

378

379

380

381

382

\section{Discussion}

This study aimed at creating novel antivirals for the treatment of HBV infection by combining immune stimulatory and gene silencing potentials of RNA-olignucleotides in a single molecule. We first showed that 3p-RNA, a triphosphated dsRNA serving as RIG-I ligand, induces an antiviral type-I IFN response in HBV replicating hepatocytes. 3p-RNA potently, but transiently controlled HBV. To enhance and prolong the antiviral effect, we designed siRNAs targeting the $3^{\prime}$-end of all HBV RNAs and investigated whether they can be furnished with a 5' triphosphate and act as RIG-I ligands - adding immunostimulatory potential to the siRNA. HBV specific 3p-siRNAs induced a type-I IFN response comparable to $3 p-R N A$ and induced cleavage of HBV RNAs comparable to corresponding siRNA. When used for antiviral treatment, bi-functional 3p-siRNAs proved superior to siRNA and 3p-RNA. They more potently and longer lasting controlled HBV replication in vitro in human hepatocyte cultures and in vivo in livers of HBV transgenic mice.

HBV-specific siRNAs are powerful tools to target viral genes and inhibit HBV replication in vitro ${ }^{19}$ and in vivo ${ }^{3,4,6,20}$. Viruses usually occur in several genotypes and in addition show a high sequence variation restricting siRNA targeting to highly conserved regions within the virus genome. We carefully selected three novel siRNAs matching highly conserved genomic sequences. Notably, si1.1 targets all known HBV genotypes. Since HBV RNAs terminate at a common polyadenylation signal directly downstream of the $\mathrm{X}$ gene ${ }^{21}$, our siRNAs target multiple HBV RNAs: si-1.1 and si-1.2 target all HBV RNAs, si-1.3 targets all except the X RNA (Fig. 3A). In our experiments we cofirmed that the siRNAs are active against HBV genotype $A$, and D. Targeting of highly conserved HBV sequences makes the selection of escape mutations, which could hamper siRNA binding, very unlikely. Indeed, we found no HBV sequence variation in $3 p-1.2$ or si-1.2 treated hepatocytes (data not shown).

To treat HBV infection, we wanted to combine gene silencing with the immunostimulatory capacity of RNA. Toll-like receptors 7 and 8 may recognize synthetic ssRNA and dsRNA depending on sequence motives ${ }^{22,23}$. However, this is restricted to cells of the innate 
383 immune system. Furthermore, it restricts the selection of siRNA target sequences and

384 makes it very difficult to match highly conserved viral sequences.

385 We therefore decided to target the ubiquitously expressed cytosolic helicase RIG-I. RIG-I is expressed in HBV infected hepatocytes. Stimulation of cells with IFN further increased its expression ${ }^{28}$. RIG-I activation requires the presence of a triphosphate group at the 5 -end 388 of an RNA ${ }^{7,8,24-27}$. The optimal ligand is short, double-stranded $5^{\prime}$-triphosphate RNA. This 389 allows converting siRNAs into RIG-I ligands ${ }^{9}$ and explains why all three HBV-specific $3 p-$ 390 siRNAs in this study induced a type-I IFN response dependent on RIG-I expression. Our 391 experiments, however, cannot exclude that 3p-RNA and 3p-siRNA exerts additional 392 antiviral effects besides triggering and IFN response via RIG-I.

393 In vivo, hepatocytes and non-hepatocytes such as liver macrophages and liver sinusoidal 394 endothelial cells took up fluorescently labeled 3p-RNA (data not shown). Since they secrete 395 IFN upon 3p-RNA uptake (Supplementary Fig. 2), non-parenchymal liver cells contribute to 396 the antiviral activity of RIG-I ligands. Type-I IFN is long known to control HBV infection by 397 the activation of IFN induced pathways, which inhibits the transcription of HBV RNAs at 398 transcriptional and posttranscriptional levels ${ }^{29}$, prevents the formation of replication399 competent HBV capsids ${ }^{30}$ and activates effector $\mathrm{T}$ cell responses ${ }^{31}$. Notably, treatment 400 with exogenous IFN $\alpha 2 a$ (even at doses corresponding to 50.000 IU per human liver) was 401 less effective in reducing HBV replication than 3p-RNA or 3p-siRNA and addition of 402 lamivudine or other nucleos(t)ide analogues didn't show any additive effect (Supplementary 403 Fig. 3).

$4043 p$-siRNA induced cleavage of HBV RNAs similar to siRNA proving that $3 p$-siRNAs are truly 405 bi-functional. However, it is unlikely that the same 3p-siRNA molecule binds and activates 406 RIG-I and induces RNA cleavage. Since we observed that RNA interference activity of 3p4071.2 was lower than that of si-1.2 (Fig. 3C), we rather suggest that Dicer and RIG-I compete 408 for the binding of 3p-RNA.

409 Taken together, our newly designed 3p-siRNA proved superior in controlling HBV 410 replication over sequence-identical siRNA and 3p-RNA. Thus, 3p-siRNAs are promising, bi- 
411 functional antiviral molecules targeting HBV by combining immunostimulation and gene

412 silencing.

\section{Acknowledgements}

We are grateful to Olaf Utermöhlen, Martin Krönke and Katja Wiegmann for their support with animal housing and helpful discussions, Ke Zhang for sequence analysis and Raindy

418 Tedjokusumo and Theresa Asen for excellent technical assistance. The authors want to especially acknowledge Heinz Schaller for providing reagents and mouse line HBV1.3xfs.

\section{References}

1. Lok AS, McMahon BJ. Chronic hepatitis B: update 2009. Hepatology 2009;50:661-2.

2. Beutler B, Eidenschenk C, Crozat K, Imler JL, Takeuchi O, Hoffmann JA, Akira S. Genetic analysis of resistance to viral infection. Nat Rev Immunol 2007;7:753-66.

3. McCaffrey AP, Nakai H, Pandey K, Huang Z, Salazar FH, Xu H, Wieland SF, Marion

4. Klein C, Bock CT, Wedemeyer H, Wustefeld T, Locarnini S, Dienes HP, Kubicka S, Manns MP, Trautwein C. Inhibition of hepatitis B virus replication in vivo by nucleoside analogues and siRNA. Gastroenterology 2003;125:9-18.

5. Shlomai A, Shaul Y. Inhibition of hepatitis B virus expression and replication by RNA interference. Hepatology 2003;37:764-70.

6. Morrissey DV, Lockridge JA, Shaw L, Blanchard K, Jensen K, Breen W, Hartsough K, Machemer L, Radka S, Jadhav V, Vaish N, Zinnen S, Vargeese C, Bowman K, Shaffer CS, Jeffs LB, Judge A, MacLachlan I, Polisky B. Potent and persistent in vivo anti-HBV activity of chemically modified siRNAs. Nat Biotechnol 2005;23:1002-7.

7. Hornung V, Ellegast J, Kim S, Brzozka K, Jung A, Kato H, Poeck H, Akira S, for RIG-I. Science 2006;314:994-7.

8. Pichlmair A, Schulz O, Tan CP, Naslund TI, Liljestrom P, Weber F, Reis e Sousa C. RIG-I-mediated antiviral responses to single-stranded RNA bearing 5'-phosphates. Science 2006;314:997-1001. 
443

444

445

446

447

448

449

450

451

452

453

454

455

456

457

458

459

460

461

462

463

464

465

466

467

468

469

470

471

472

473

474

475

476

477

9. Poeck H, Besch R, Maihoefer C, Renn M, Tormo D, Morskaya SS, Kirschnek S, Gaffal E, Landsberg J, Hellmuth J, Schmidt A, Anz D, Bscheider M, Schwerd T, Berking C, Bourquin C, Kalinke U, Kremmer E, Kato H, Akira S, Meyers R, Hacker G, Neuenhahn M, Busch D, Ruland J, Rothenfusser S, Prinz M, Hornung V, Endres S, Tuting T, Hartmann G. 5'-Triphosphate-siRNA: turning gene silencing and Rig-I activation against melanoma. Nat Med 2008;14:1256-63.

10. Barchet W, Wimmenauer V, Schlee M, Hartmann G. Accessing the therapeutic potential of immunostimulatory nucleic acids. Curr Opin Immunol 2008;20:389-95.

11. Jost $S$, Turelli $P$, Mangeat $B$, Protzer $U$, Trono $D$. Induction of antiviral cytidine deaminases does not explain the inhibition of hepatitis $B$ virus replication by interferons. J Virol 2007;81:10588-96.

12. Protzer U, Seyfried S, Quasdorff M, Sass G, Svorcova M, Webb D, Bohne F, Hosel M, Schirmacher $P$, Tiegs $G$. Antiviral activity and hepatoprotection by heme oxygenase-1 in hepatitis B virus infection. Gastroenterology 2007;133:1156-65.

13. Schulze-Bergkamen $H$, Untergasser A, Dax A, Vogel H, Buchler $P$, Klar E, Lehnert $T$, Friess H, Buchler MW, Kirschfink M, Stremmel W, Krammer PH, Muller M, Protzer U. Primary human hepatocytes--a valuable tool for investigation of apoptosis and hepatitis B virus infection. J Hepatol 2003;38:736-44.

14. Dumortier J, Schonig K, Oberwinkler H, Low R, Giese T, Bujard H, Schirmacher P, Protzer U. Liver-specific expression of interferon gamma following adenoviral gene transfer controls hepatitis B virus replication in mice. Gene Ther 2005;12:668-77.

15. Untergasser A, Zedler U, Langenkamp A, Hosel M, Quasdorff M, Esser K, Dienes HP, Tappertzhofen B, Kolanus W, Protzer U. Dendritic cells take up viral antigens but do not support the early steps of hepatitis B virus infection. Hepatology 2006;43:539-47.

16. Weber O, Schlemmer KH, Hartmann E, Hagelschuer I, Paessens A, Graef E, Deres K, Goldmann S, Niewoehner U, Stoltefuss J, Haebich D, Ruebsamen-Waigmann H, Wohlfeil S. Inhibition of human hepatitis B virus (HBV) by a novel non-nucleosidic compound in a transgenic mouse model. Antiviral Res 2002;54:69-78.

17. Nallagatla SR, Hwang J, Toroney R, Zheng X, Cameron CE, Bevilacqua PC. 5'triphosphate-dependent activation of PKR by RNAs with short stem-loops. Science 2007;318:1455-8.

18. Quasdorff M, Hosel M, Odenthal M, Zedler U, Bohne F, Gripon P, Dienes HP, Drebber U, Stippel D, Goeser T, Protzer U. A concerted action of HNF4alpha and HNF1alpha links hepatitis $B$ virus replication to hepatocyte differentiation. Cell Microbiol 2008;10:1478-90. 
19. Hamasaki K, Nakao K, Matsumoto K, Ichikawa T, Ishikawa H, Eguchi K. Short interfering RNA-directed inhibition of hepatitis $B$ virus replication. FEBS Lett 2003;543:51-4.

20. Giladi H, Ketzinel-Gilad M, Rivkin L, Felig Y, Nussbaum O, Galun E. Small interfering RNA inhibits hepatitis B virus replication in mice. Mol Ther 2003;8:769-76.

21. Cattaneo $\mathrm{R}$, Will $\mathrm{H}$, Schaller $\mathrm{H}$. Hepatitis $B$ virus transcription in the infected liver. EMBO J 1984;3:2191-6.

22. Hornung V, Guenthner-Biller M, Bourquin C, Ablasser A, Schlee M, Uematsu S, Noronha A, Manoharan M, Akira S, de Fougerolles A, Endres S, Hartmann G. Sequence-specific potent induction of IFN-alpha by short interfering RNA in plasmacytoid dendritic cells through TLR7. Nat Med 2005;11:263-70.

23. Judge AD, Sood V, Shaw JR, Fang D, McClintock K, MacLachlan I. Sequencedependent stimulation of the mammalian innate immune response by synthetic siRNA. Nat Biotechnol 2005;23:457-62.

24. Kim DH, Longo M, Han Y, Lundberg P, Cantin E, Rossi JJ. Interferon induction by siRNAs and ssRNAs synthesized by phage polymerase. Nat Biotechnol 2004;22:321-5.

25. Cui S, Eisenacher K, Kirchhofer A, Brzozka K, Lammens A, Lammens K, Fujita T, Conzelmann KK, Krug A, Hopfner KP. The C-terminal regulatory domain is the RNA 5'triphosphate sensor of RIG-I. Mol Cell 2008;29:169-79.

26. Saito T, Owen DM, Jiang F, Marcotrigiano J, Gale M, Jr. Innate immunity induced by composition-dependent RIG-I recognition of hepatitis C virus RNA. Nature 2008;454:523-7.

27. Takahasi K, Yoneyama M, Nishihori T, Hirai R, Kumeta H, Narita R, Gale M, Jr., Inagaki F, Fujita T. Nonself RNA-sensing mechanism of RIG-I helicase and activation of antiviral immune responses. Mol Cell 2008;29:428-40.

28. Bowie AG, Unterholzner L. Viral evasion and subversion of pattern-recognition receptor signalling. Nat Rev Immunol 2008;8:911-22.

29. Uprichard SL, Wieland SF, Althage A, Chisari FV. Transcriptional and posttranscriptional control of hepatitis B virus gene expression. Proc Natl Acad Sci U S A 2003;100:1310-5.

30. Wieland SF, Eustaquio A, Whitten-Bauer C, Boyd B, Chisari FV. Interferon prevents formation of replication-competent hepatitis $B$ virus RNA-containing nucleocapsids. Proc Natl Acad Sci U S A 2005;102:9913-7. 
- Ebert et al.: 5' triphosphated siRNA control HBV -

511 31. Yang PL, Althage A, Chung J, Maier H, Wieland S, Isogawa M, Chisari FV. Immune

512 effectors required for hepatitis B virus clearance. Proc Natl Acad Sci U S A

$513 \quad 2010 ; 107: 798-802$.

514

515 
- Ebert et al.: 5' triphosphated siRNA control HBV -

\section{Tables}

517

518 Table 1: Sequences of in vitro transcribed 3p-RNAs and chemically synthesized siRNAs

Name 3p-RNA

$3 p-1.1$

$3 p-1.2$

$3 p-1.3$

si-1.1*

si-1.2*

$\mathrm{si}-1.3^{*}$

Ctrl siRNA (HCV)*

RIG-I siRNA* sense strand 5'- 3'

$3 p-$ antisense strand 5'-3'

3p-UCAAACAGAGGUCGCAUGC

GCAUGCGACCUCUGUUUGA

3p-UUUCACCUCUGCCUAAUCA 3p-UGAUUAGGCAGAGGUGAAA

3p-CGACCUUGAGGCAUACUUC 3p-GAAGUAUGCCUCAAGGUCG

3p-CUAUUAACAGGCCUAUUGA 3p-UCAAUAGGCCUGUUAAUAG

UUUCACCUCUGCCUAAUCA UGAUUAGGCAGAGGUGAAA

CGACCUUGAGGCAUACUUC GAAGUAUGCCUCAAGGUCG

CUAUUAACAGGCCUAUUGA UCAAUAGGCCUGUUAAUAG

CUGAUAGGGUGCUUGCGAG CUCGCAAGCACCCUAUCAG

AAACAGCGAUUAGGCACUA UAGUGCCUAAUCGCUGUUU

Ctrl-RNA (Poly A)

AAAAAAAAAAAAAAAAAAA

519 * to all chemically synthesized siRNAs a -dTdT was added at the 3' end to increase stability 


\section{$522 \quad$ Figure Legends}

524 Figure 1: Antiviral effect of 3p-RNA. HBV infected primary human hepatocytes (A) and

525 HBV transgenic mice (B) were treated with 3p-RNA, negative control polyA-RNA (Ctrl-RNA)

526 or nucleic acid delivery reagents only (mock). Primary hepatocytes were additionally treated 527 with poly(l:C) as positive control. Progeny HBV DNA levels (left panels) were determined by 528 quantitative real time PCR, HBeAg and HBsAg levels (middle panels) by immunoassays in 529 hepatocyte culture medium or mouse serum day 6 after treatment. Intrahepatic pregenomic 530 HBV RNA (pgRNA) levels (right panels) were quantified relative to GAPDH by real-time RT531 PCR. Mean values from mock treated cells or mice, respectively, were set to $100 \%$. Data 532 are shown as mean $\pm \mathrm{SD}, \mathrm{n}=3\left({ }^{* *} \mathrm{p}<0.01,{ }^{* * *} \mathrm{p}<0.001\right.$, t-test $)$.

Figure 2: 3p-RNA induces IFN-ß production through RIG-I in HBV replicating liver cells. (A) Hepatoma HepG2-H1.3 cells were transfected with increasing concentrations of 3p-RNA and cell viability was monitored from d 1 to 16 post transfection (p.tr.). (B) HepG2H1.3 cells (left panel), HBV infected primary human hepatocytes $(\mathrm{PHH})$ (middle panel) and HBV transgenic mice (right panel) were treated with 3p-RNA, polyA-RNA (Ctrl-RNA) as negative and poly(l:C) as positive control. Nucleic acid delivery reagents only served as mock control. IFN- $\alpha$ levels in mouse sera were determined by cytokine bead assay at

541 indicated time points post injection (p. inj). Hepatocellular IFN-ß (upper row) and 2'-5'-OAS 542 (lower row) mRNA levels were analyzed by quantitative RT-PCR relative to GAPDH and 543 normalized to mock treatment (set to 1). (C) HepG2-H1.3 cells and PHH were cultured with $544(+)$ or without (-) exogenous IFN- $\alpha(1000 \mathrm{U} / \mathrm{ml})$ or transfected with 3p-RNA. After 36h RIG-I expression was determined by Western blot analysis using ß-actin as loading control. (D) HepG2-H1.3 cells were transfected with siRNA against RIG-I, lysed at indicated time points

547 post transfection (p. tr.) and analyzed for RIG-I expression by Western blot analysis; ß-actin 548 served as loading control. (E) Knock-down of Rig-I in HepG2-H1.3 cells before 3p-RNA 
549 treatment and measuring IFN- $ß$ expression at day 1; mean values of cells treated with

550 control siRNA was set to $100 \%$. (F) HepG2 H1.3 cells were transfected with siRNA and

551 transfected again with 3p-RNA 72h later. 4 days later $\mathrm{HBeAg}$ and $\mathrm{HBsAg}$ secreted into the

552 cell culture medium was quantified relative to control siRNA. Data are given as mean \pm SD,

$553 \mathrm{n}=3 ;{ }^{*} \mathrm{p}<0.05$ (t-test).

554

555 Figure 3: HBV specific 3p-siRNAs are bifunctional. (A) HBV specific siRNAs (indicated 556 by arrows) were designed to target the 3' end common to all HBV RNAs. From 3.5 kb RNA 557 precore/core and polymerase proteins, from $2.4 \mathrm{~kb}$ RNA the large surface protein ( $\mathrm{L}$, 558 consisting of preS1, preS2 and S domains), from $2.1 \mathrm{~kb}$ RNA middle (M, consisting of 559 preS2 and S) and small (S) surface proteins and from $0.7 \mathrm{~kb}$ RNA the $\mathrm{X}$ protein are 560 translated. (B) HepG2-H1.3 cells were transfected with siRNA (si-1.2) or 3p-siRNA (3p-1.2).

561 Cells were analyzed for IFN- $ß$ expression normalized to GAPDH by real-time RT-PCR after

562 12h. Mock treated cells were set to 1. (C) 5-RACE PCR analysis of RNA extracted from 563 HepG2-H1.3 cells treated with si-1.2 and 3p-1.2 or HCV sequence specific siRNA (si-Ctrl), 564 poly $(\mathrm{l}: \mathrm{C})$ or $3 p-\mathrm{RNA}$ as control at $\mathrm{d} 4 \mathrm{p}$. tr.. The arrow marks the $136 \mathrm{bp}$ amplification product expected after si-1.2 induced cleavage. (D) HepG2-H1.3 cells and (E) HBV infected primary human hepatocytes were treated with indicated 3p-siRNA. HBV DNA (left panels), HBeAg and HBsAg levels (right panels) secreted into the cell culture medium at d8 are given. (F) Northern blot analysis at d8 p.tr. shows HBV RNA levels in HepG2-H1.3 cells

569 transfected with 3p-siRNA. Pregenomic $(3.5 \mathrm{~kb})$ and subgenomic $(2.4$ and $2.1 \mathrm{~kb}) \mathrm{HBV}$

570 RNAs are indicated. GAPDH serves as a loading control. In B, D and E mean \pm SD from 571 three, in $C$ one representative experiment are shown; ${ }^{*} p<0.05,{ }^{* *} p<0.01,{ }^{* *} p<0.001$, t-test.

573 Figure 4: The antiviral effect of $3 p-s i R N A$ s is superior to that of 3p-RNA. HepG2-H1.3 574 cells were transfected with 3p-RNA or HBV specific 3p-siRNAs (3p-1.1, 3p-1.2, 3p-1.3) and 575 analyzed at indicated time points post transfection (p. tr.). HCV specific siRNA served as 576 control (si-Ctrl). (A) Southern blot analysis of intracellular HBV replication. Circular (rc), 577 linear, single stranded (ss) HBV DNA and the HBV integrate serving as loading control are 
578 indicated. (B) Western blot analysis for HBV L- and core protein and ß-actin as loading 579 control.

Figure 5: The antiviral effect of 3p-RNA, HBV-specific siRNA and 3p-siRNA. HepG2-

$582 \mathrm{H} 1.3$ cells were transfected with 3p-RNA, HBV specific siRNAs (si-1.1, si-1.2, si1.3) or HBV

583 specific 3p-siRNAs (3p-1.1, 3p-1.2, 3p-1.3). HCV specific siRNA served as control (si-Ctrl).

584 (A) HBV progeny DNA and (B) HBsAg secreted into the cell culture medium at d4 and d8 585 were measured. (C) Western blot analysis of intracellular HBV core protein (ß-actin serving 586 as loading control) and (D) Southern blot analysis of intracellular HBV replication at d 8 587 p.tr.. Circular (rc), linear, single stranded (ss) HBV DNA and the HBV integrate serving as 588 loading control are indicated. (E) Over a culture period of 16 days, progeny HBV DNA 589 levels were determined by real-time PCR and $(\mathbf{F})$ secreted HBeAg levels were measured by 590 ELISA. Mean \pm SD from triplicate wells are given; ${ }^{*} p<0.05,{ }^{* *} p<0.01,{ }^{* * *} p<0.001$, t-test.

592 Figure 6: Antiviral effect of 3p-siRNA in vivo in HBV transgenic mice. HBV tg mice 593 were i.v. injected with 3p-RNA, siRNA (si-1.1, si-1.2) and 3p-siRNA (3p-1.1, 3p-1.2). HCV 594 specific siRNA served as control (si-Ctrl). (A) After $6 \mathrm{~h}$, IFN- $\alpha$ was measured in serum by 595 ELISA. (B) Intrahepatic HBV DNA was detected by Southern blot analysis using a ${ }^{32} \mathrm{P}$ 596 labeled HBV-DNA probe and $60 \mu \mathrm{g}$ total liver DNA pooled from $5 \mathrm{HBV} t \mathrm{tg}$ mice per lane at 597 day 6. DNA from HepG2-H1.3 cells indicates the size of circular (rc), linear and single 598 stranded (ss) HBV DNA. (C) Relative quantification of HBV-DNA replicative intermediates 599 relative to the HBV integrates released by HindIII digestion using a phosphoimager. (D) In 600 total liver RNA, HBV pgRNA levels were determined at $d 6$ and $d 9$ by real-time RT-PCR 601 relative to GAPDH and normalized to si-Ctrl treated mice. Mean values from si-Ctrl treated 602 mice were set to $100 \%$. In $A$ and $D$, data from four mice each are shown as mean \pm SD; $603{ }^{*} p<0.05,{ }^{* *} p<0.01$, t-test. (E) Immunohistochemistry staining for HBV core protein and (F) 604 haematoxylin / eosin staining at day 9 in liver sections of from representative animals 605 treated with si-Ctrl, si-1.2, 3p-RNA and 3p-siRNA 3p-1.2. Scale bars, $100 \mu \mathrm{m}$. 
A HBV infected primary human hepatocytes
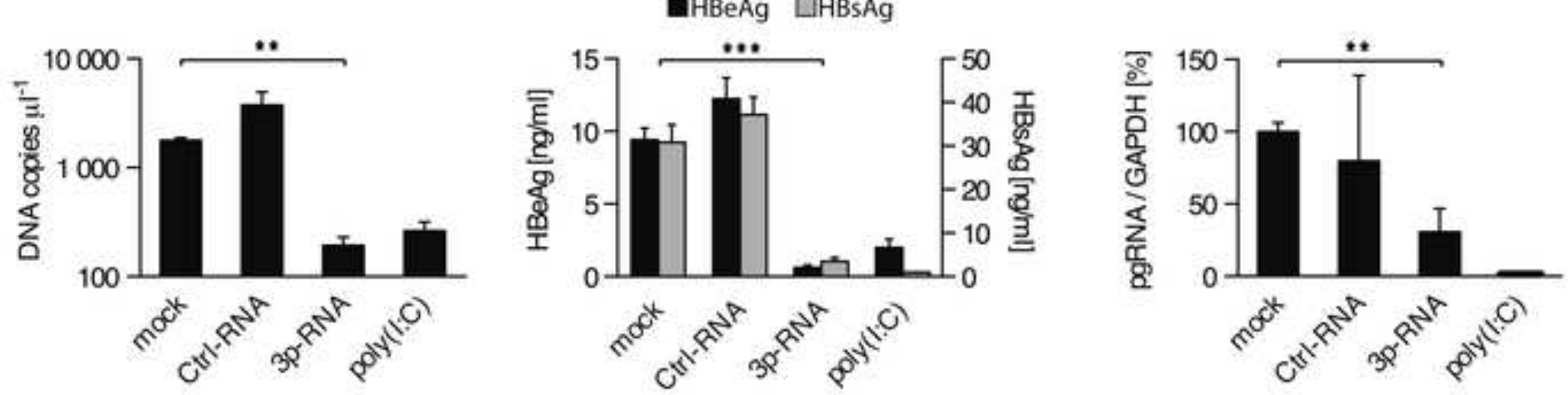

\section{B HBV transgenic mice}
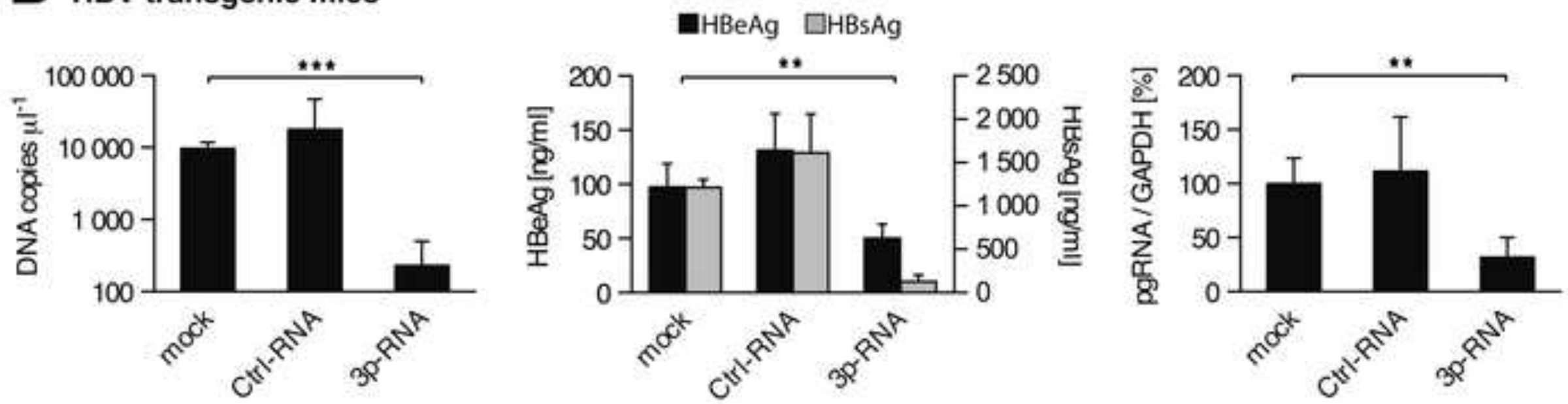


\section{Figure 2}

Click here to download high resolution image
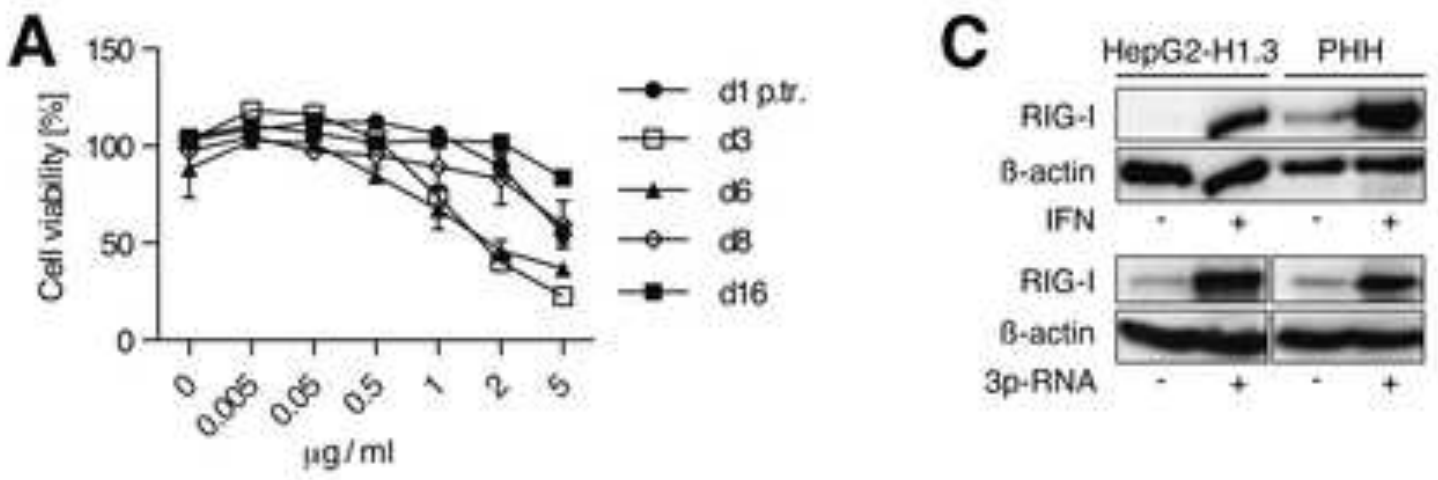

B

HepG2-H1.3
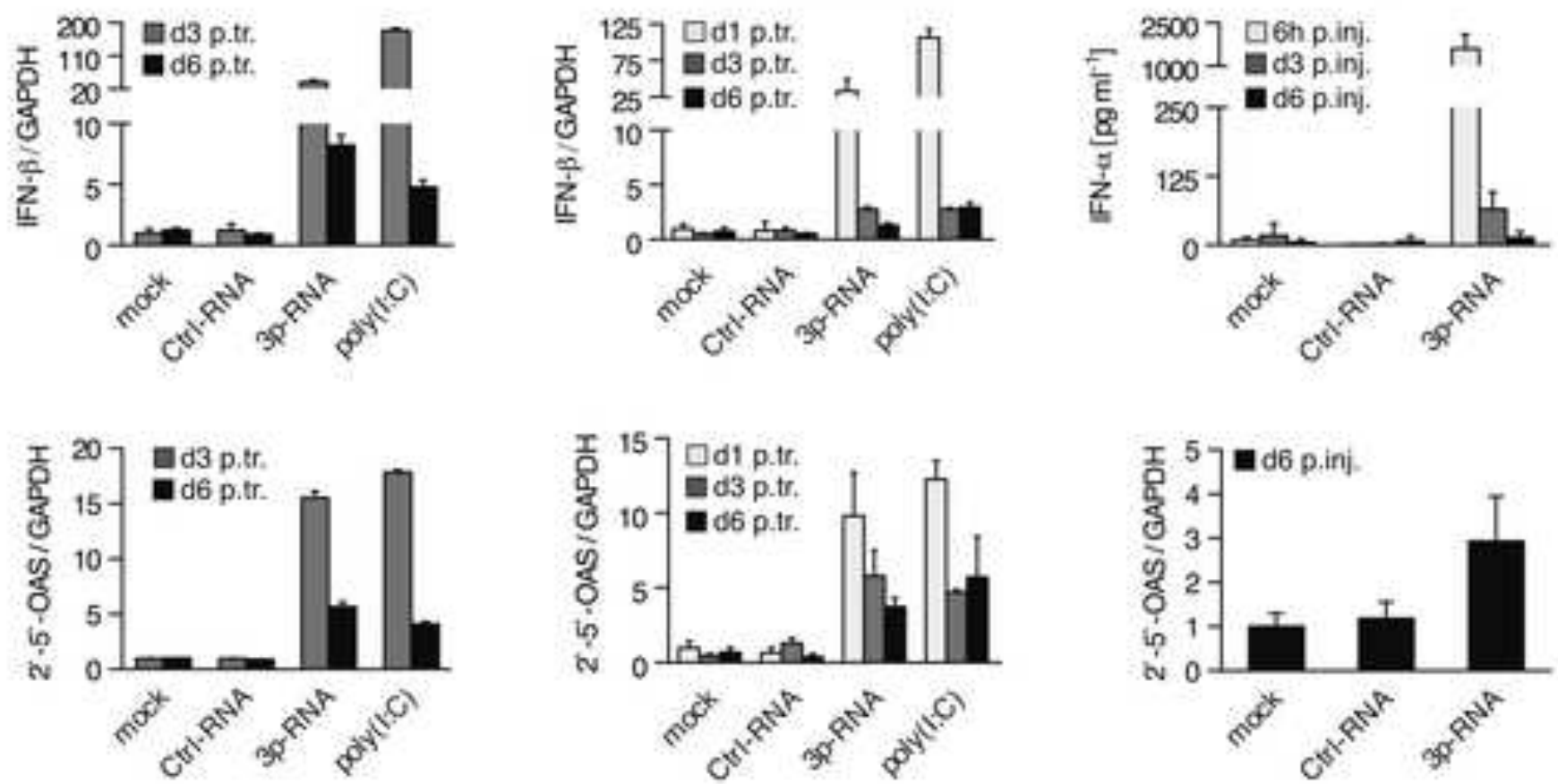

D
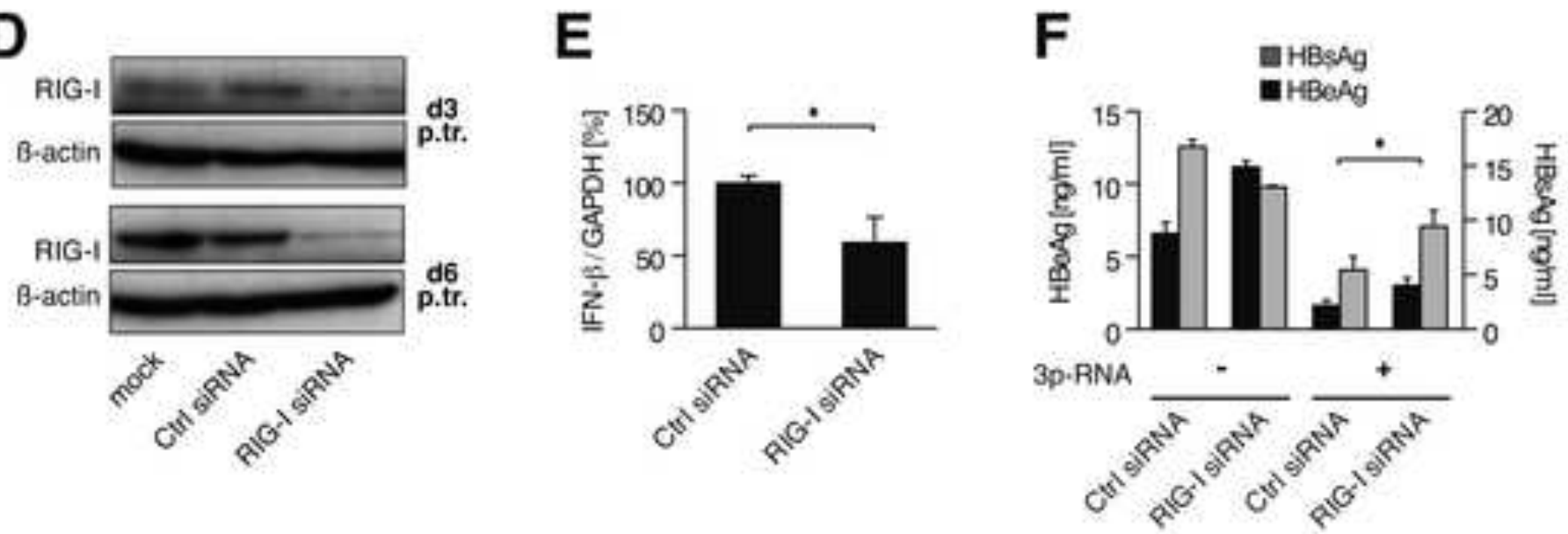
A

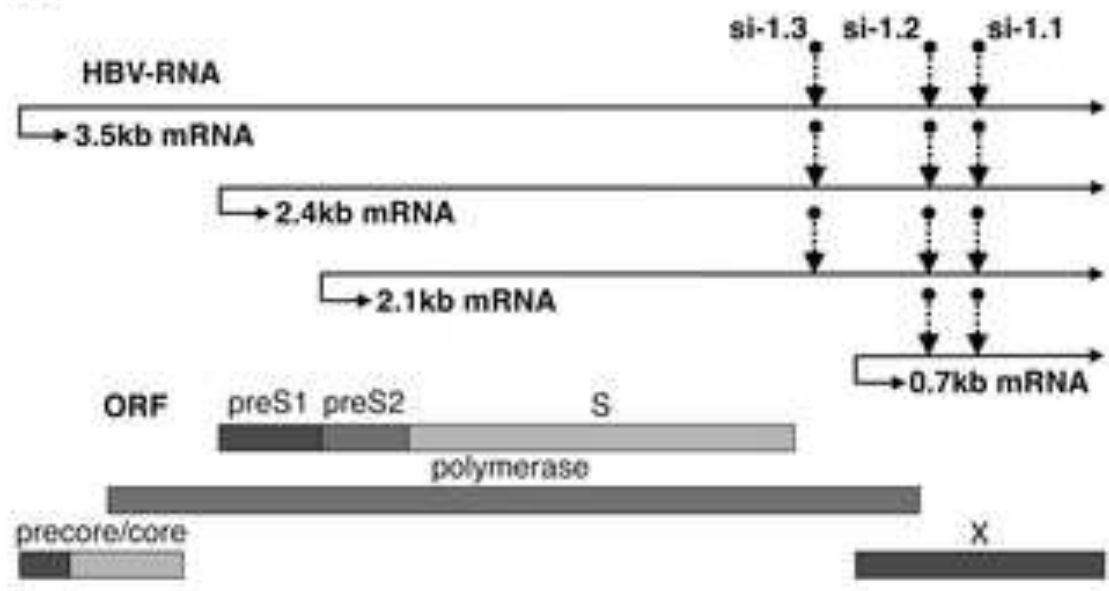

B
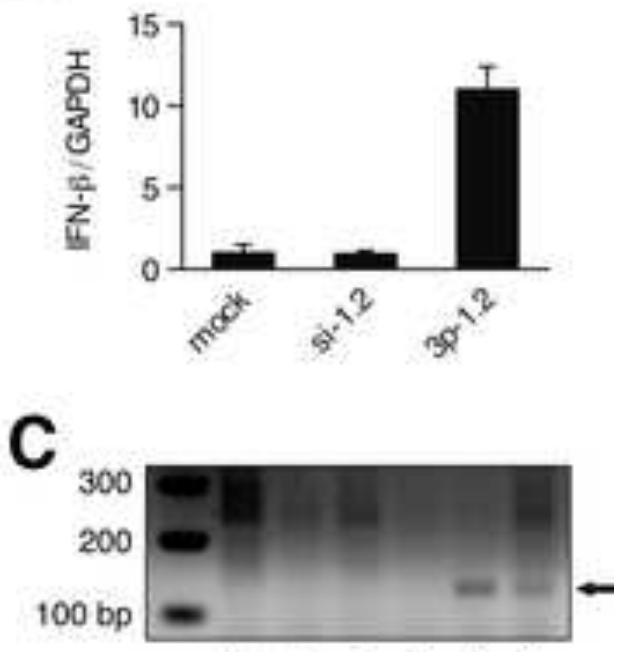

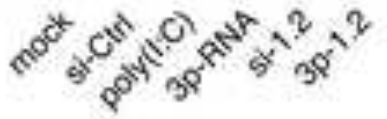

$\mathbf{F}$
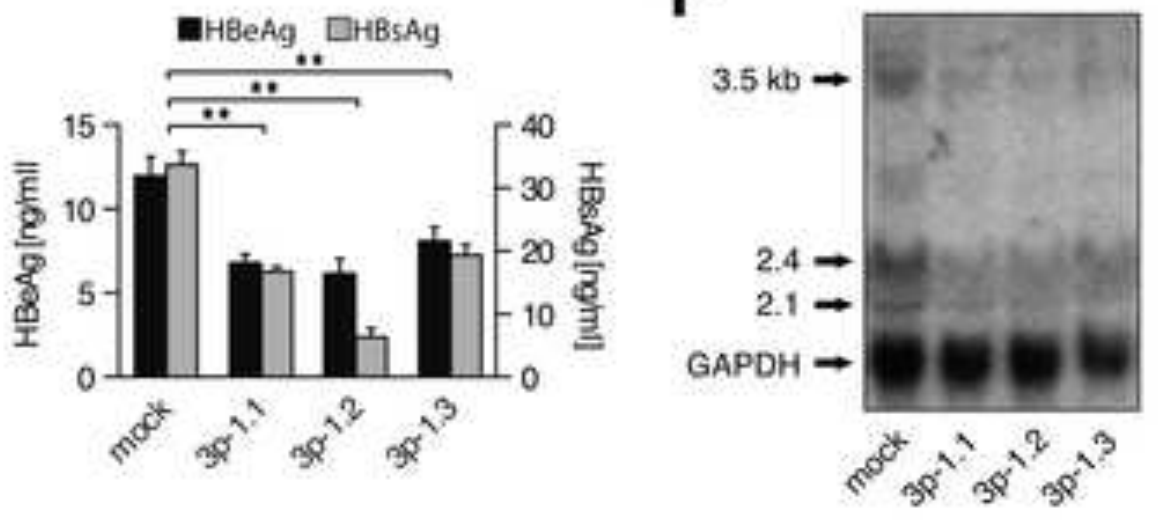

E HBV infected primary human hepatocytes
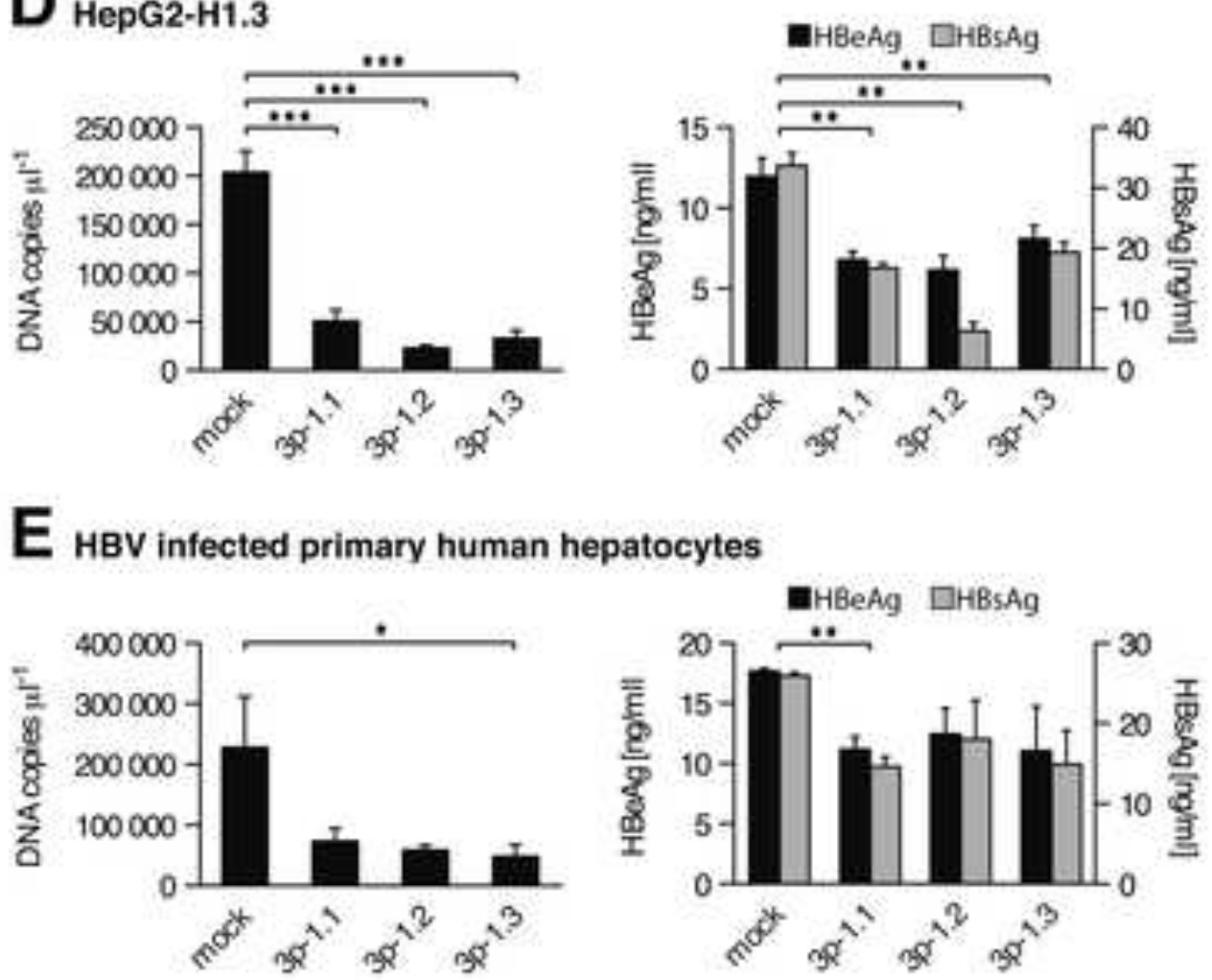


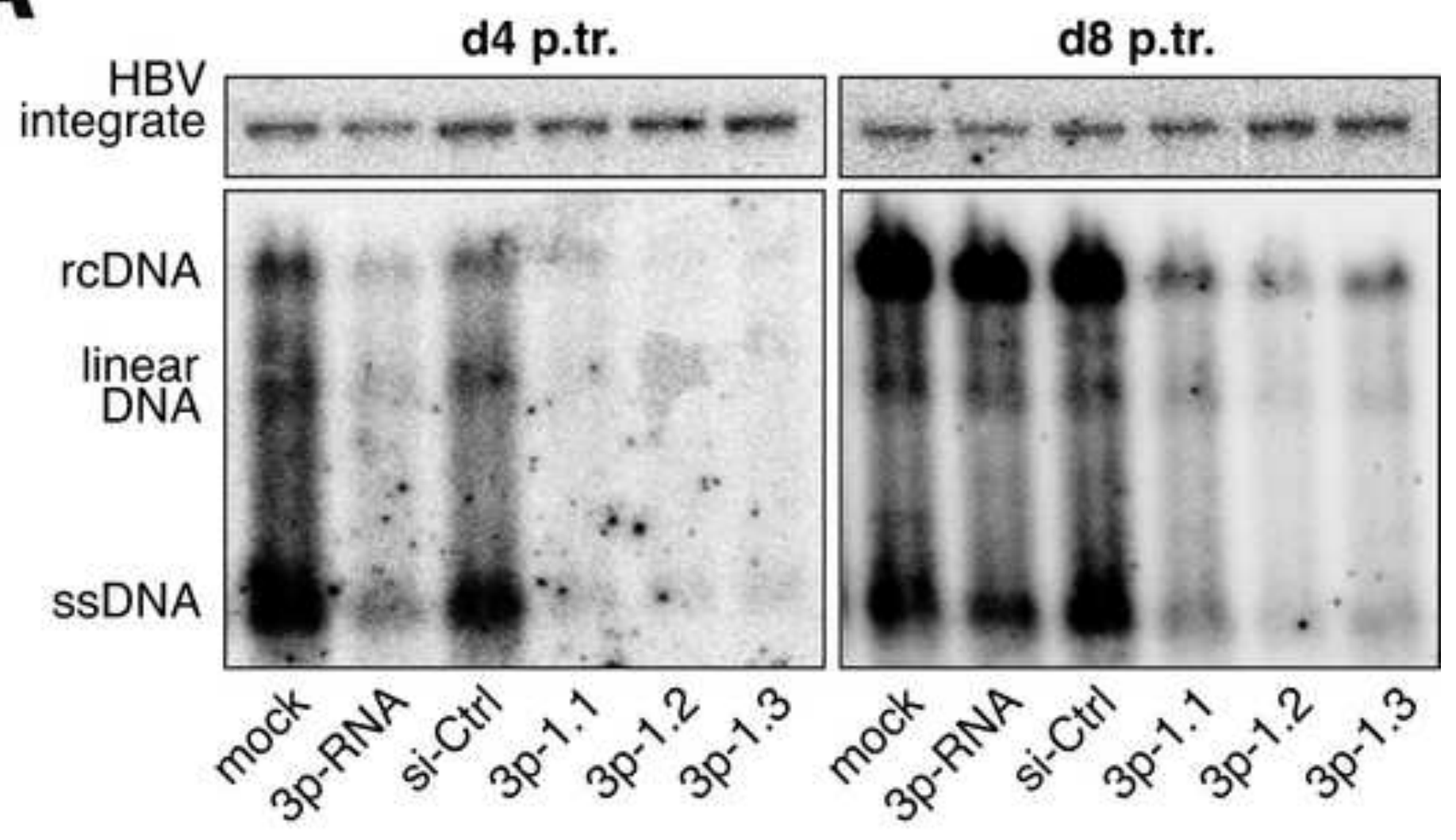

d4 p.tr.

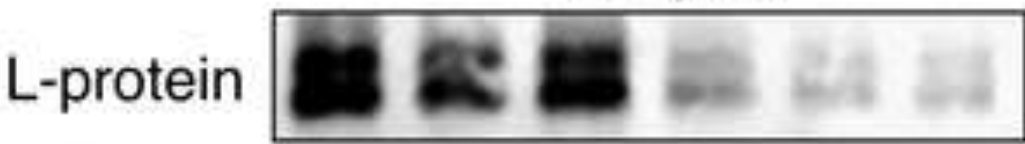

$\beta$-actin $-\infty \omega-$

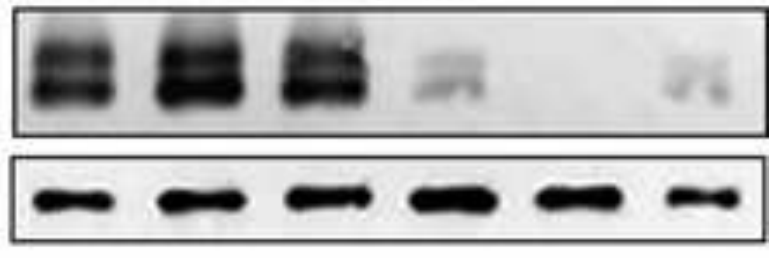

core-
protein

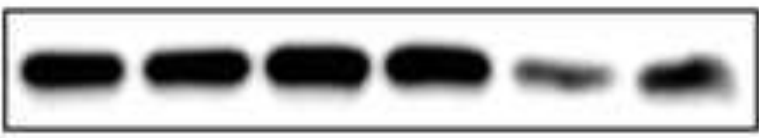

$\beta$-actin

d8 p.tr.
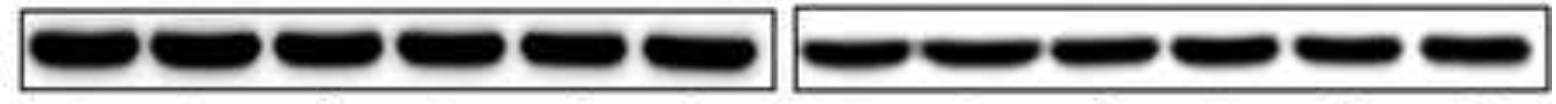

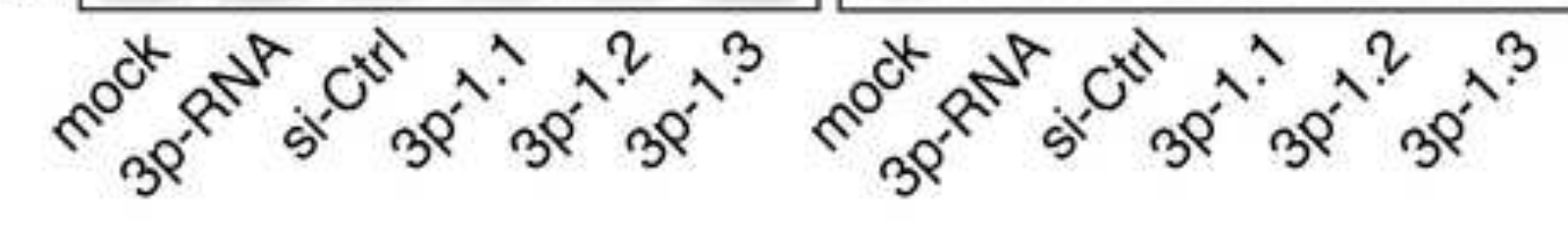

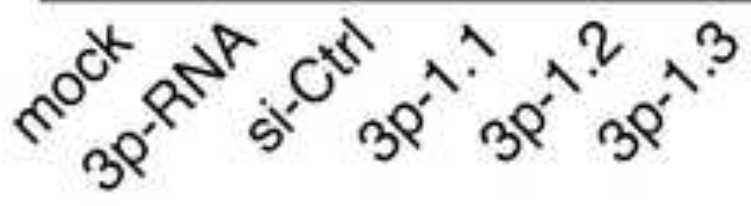




\section{Figure 5}

Click here to download high resolution image

A

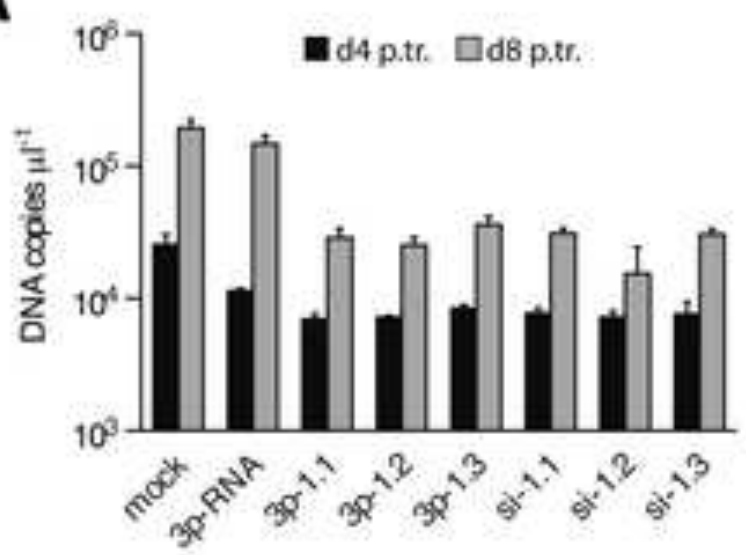

C core.
protein

$\beta$-actin

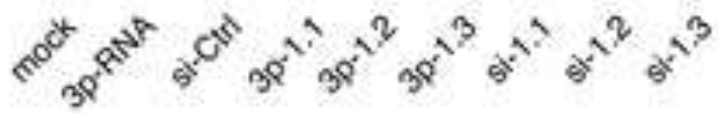

E

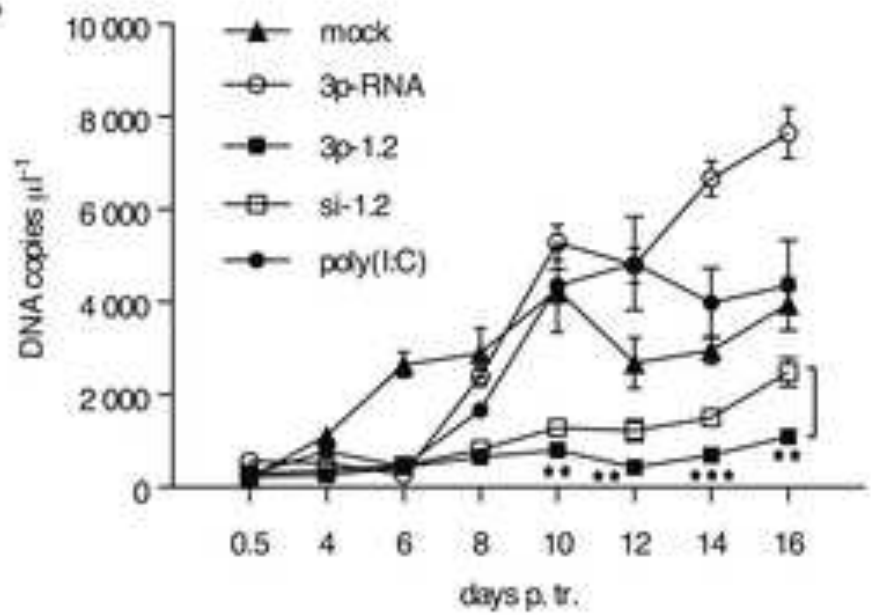

B

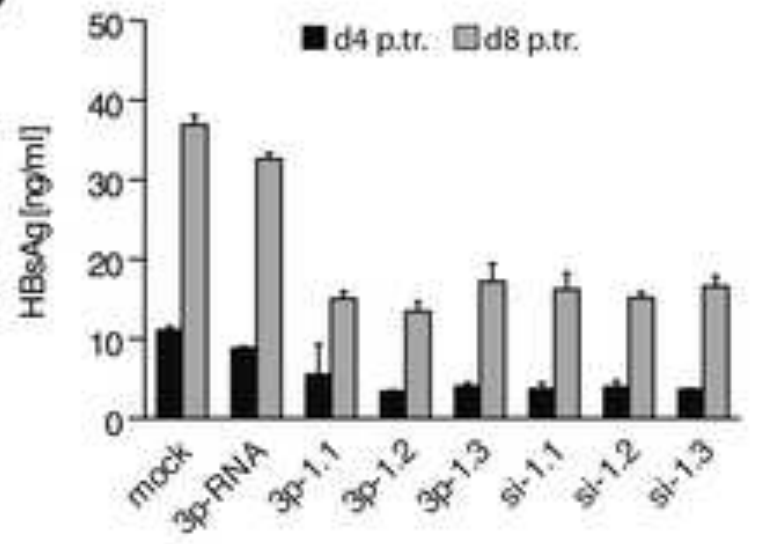

D

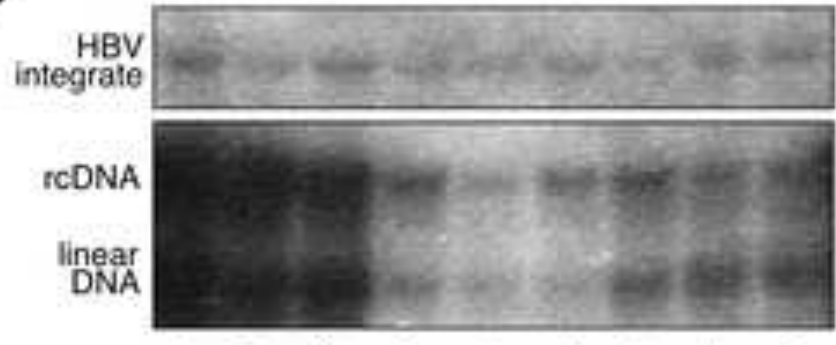

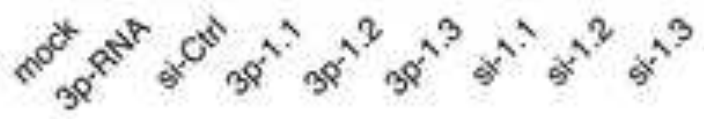

$\mathbf{F}$

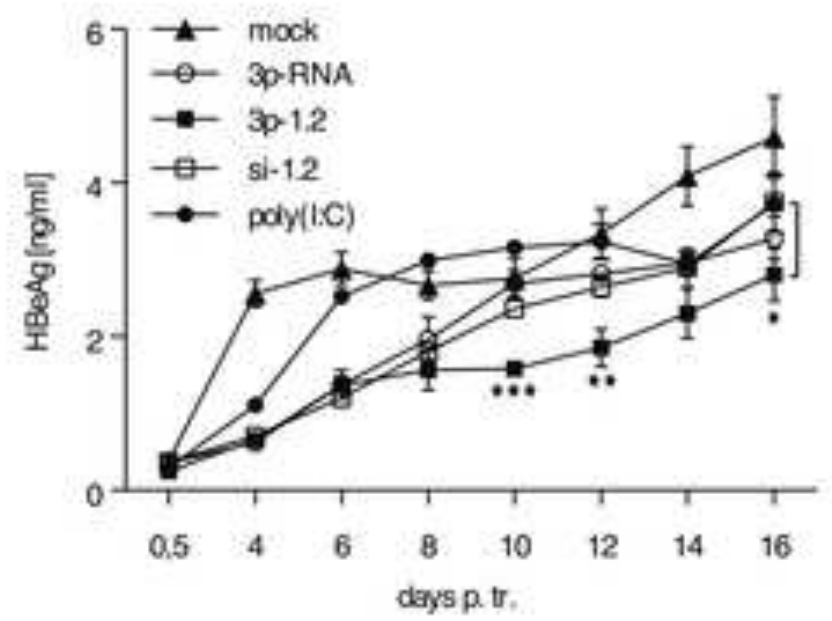




\section{Figure}

Click here to download high resolution image

A

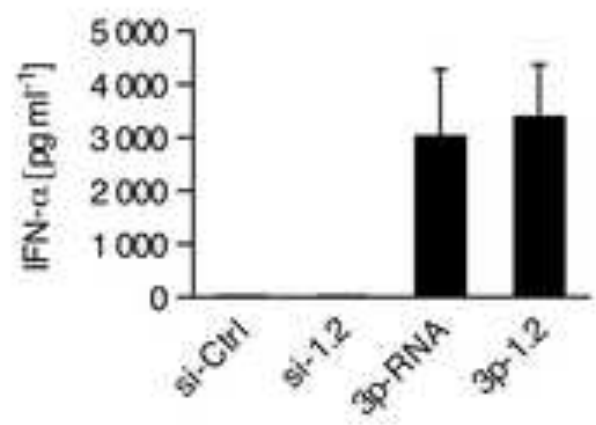

C

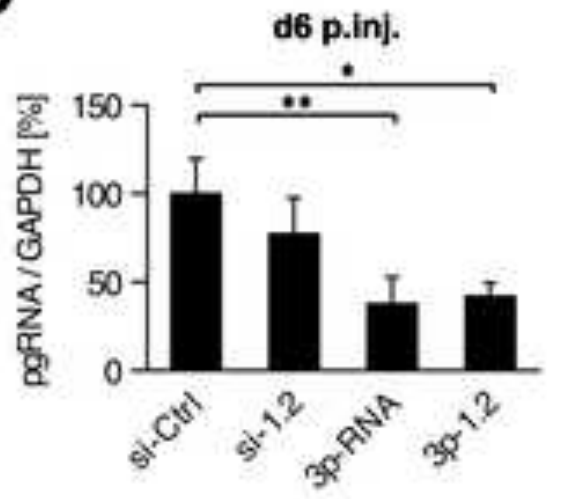

B

linear DNA
rcDNA
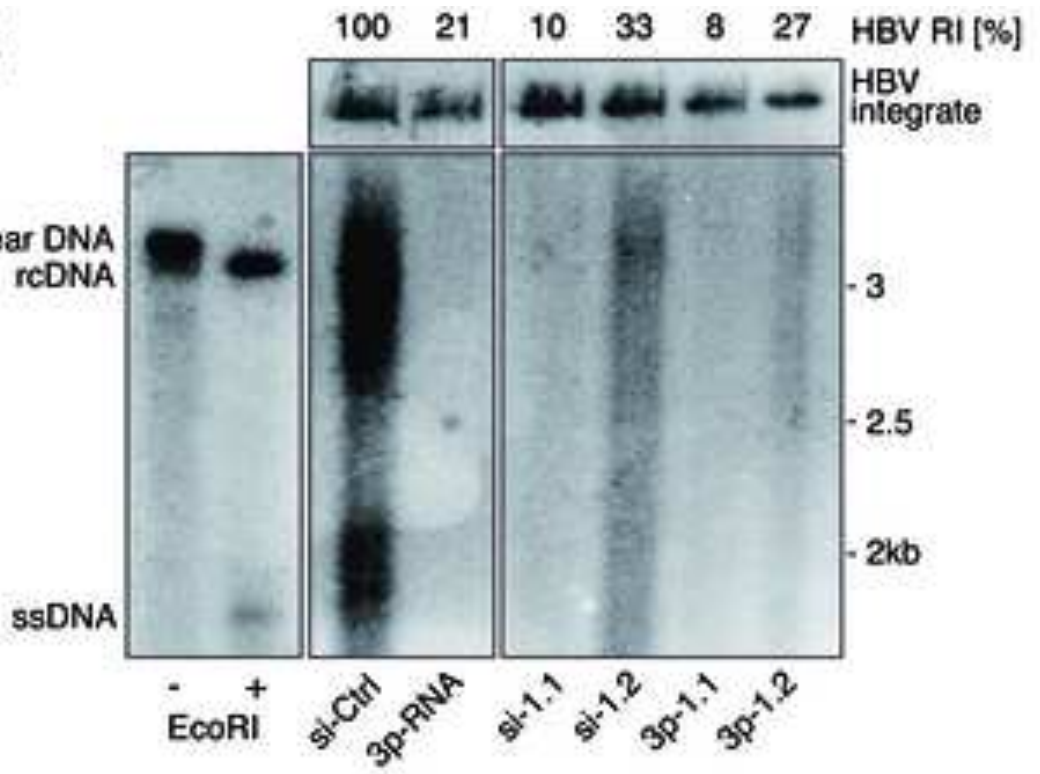

HBV transgenic mice

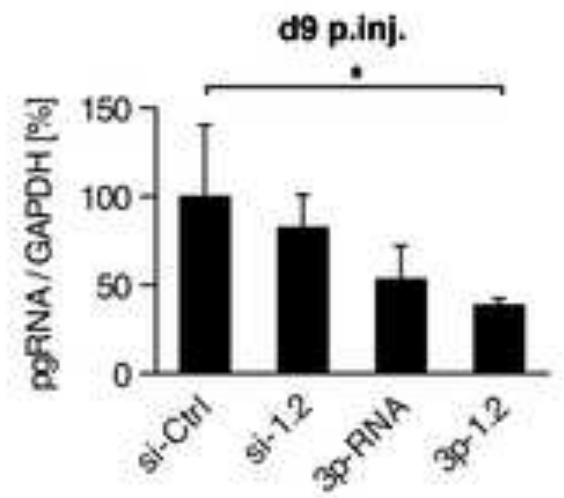

D

si-Ctri

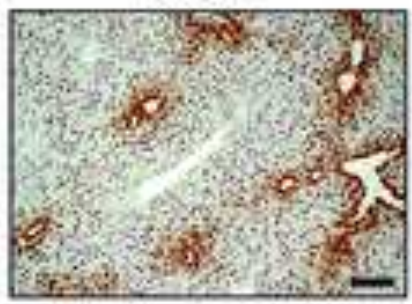

si-1.2

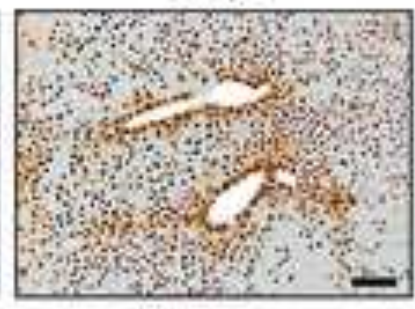

3p-ANA
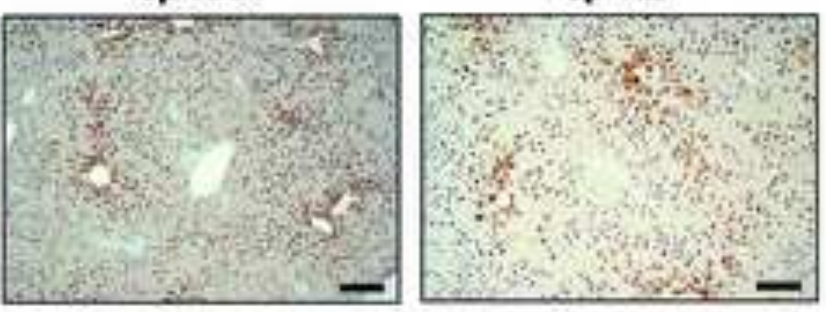

E

si-Ctri

si-1.2

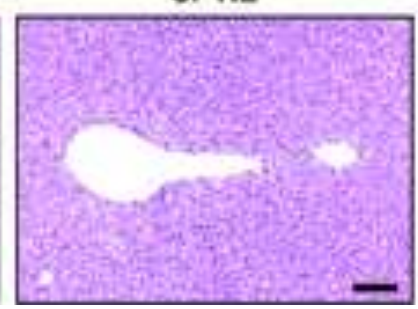

3p-ANA

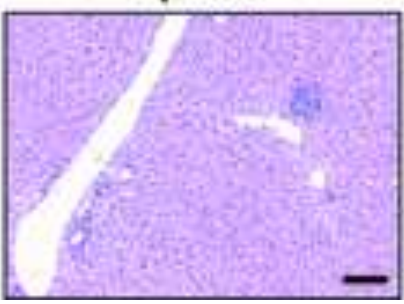

$3 p-1.2$

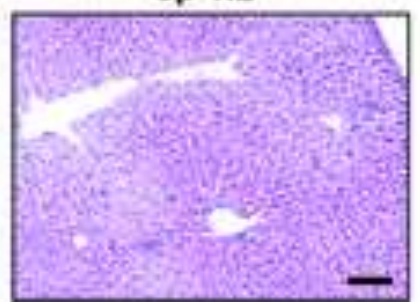


Supplementary Table: Oligonucleotides used for PCR

\begin{tabular}{|c|c|}
\hline Name & Target \\
\hline rcDNA1745 fw & HBV \\
\hline rcDNA1844 rev & HBV \\
\hline pgRNA 383 fw & HBV \\
\hline pgRNA 705 rev & HBV \\
\hline cccDNA $92 \mathrm{fw}$ & HBV \\
\hline cccDNA $2251 \mathrm{rev}$ & HBV \\
\hline HBV 3081 rev & HBV \\
\hline HBV 3075 rev & HBV \\
\hline mitoDNA 8686 fw & human / mouse \\
\hline mitoDNA 8796 rev & human / mouse \\
\hline IFN- $\beta$ fw & human \\
\hline IFN- $\beta$ rev & human \\
\hline $2^{\prime}-5^{\prime}-O A S \mathrm{fw}$ & human \\
\hline $2^{\prime}-5^{\prime}-O A S$ rev & human \\
\hline GAPDH fw & human \\
\hline GAPDH rev & human \\
\hline IFN- $\beta$ fw & mouse \\
\hline IFN- $\beta$ rev & mouse \\
\hline $2^{\prime}-5^{\circ}-\mathrm{OAS} \mathrm{fw}$ & mouse \\
\hline $2^{\prime}-5^{`}-$ OAS rev & mouse \\
\hline GAPDH fw & mouse \\
\hline GAPDH rev & mouse \\
\hline GR5 fw & - \\
\hline GeneRacer ${ }^{\mathrm{TM}}$ adaptor & - \\
\hline
\end{tabular}

Sequence 5 - 3
GGAGgGATACATAGAGGTTCCTTGA
GTTGCCCGTTTGTCCTCTAATTC
CTCCTCCAGCTTATAGACC
GTGAGTGGGCCTACAAA
GCCTATTGATTGGAAATATGT
AGCTGAGGCGGTATCTA
GACCAATTTATGCCTACAGC
TTTATGCCTACAGCCTCCTA
CCCTCTCGGCCCTCCTAATAACCT
GCCTTCTCGTATAACATCGCGTCA

GCCGCATTGACCATCT

AGTTTCGGAGGTAACCTG

CAGTTAAATCGCCGGG

AGGTTATAGCCGCCAG

GGTATCGTGGAAGGACT

GGGTGTCGCTGTTGAA

TTACACTGCCTTTGCCA

GCGTAGCTGTTGTACTTC

CAGTGGATTGGACACTCT

AGCACTTGAATGTTCACC

ACCAACTGCTTAGCCC

CCACGACGGACACATT

CGACTGGAGCACGAGGACACTGA

CGACUGGAGCACGAGGACACUGACAUGGA

CUGAAGGAGUAGAAA 


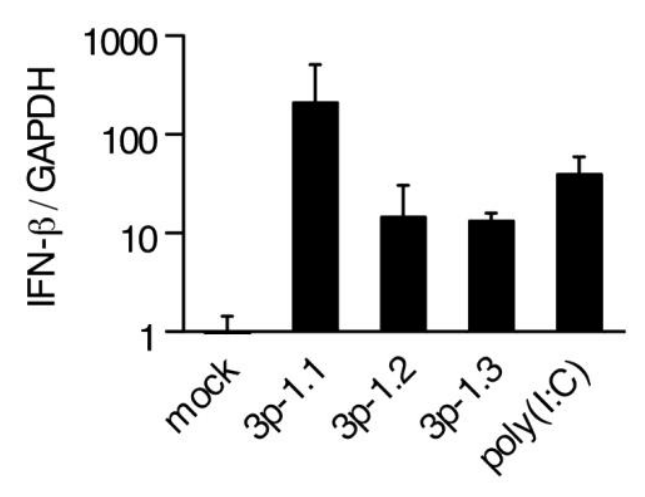

1

2 Supplementary Figure 1: Interferon induction in HepG2-H1.3 cells. HepG2 H1.3-cells 3 4

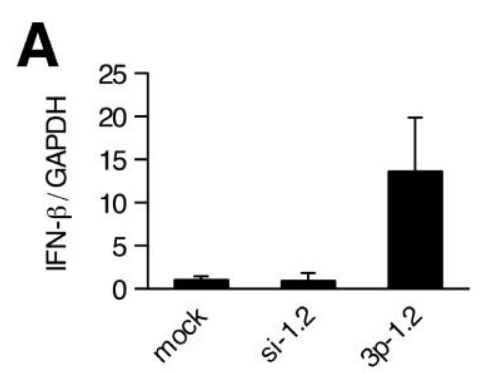

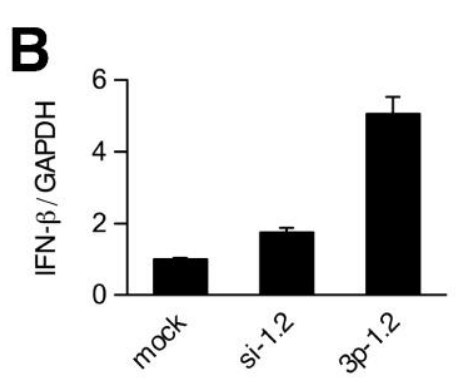

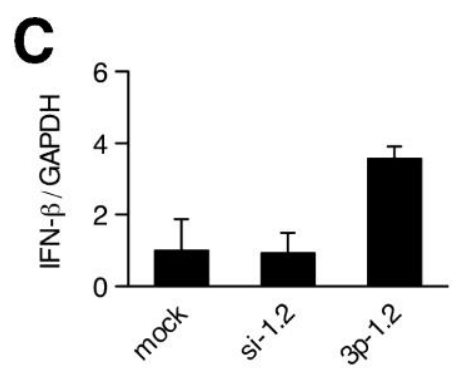

13 Supplementary Figure 2: IFN-induction of 3p-siRNA after uptake in human 14 parenchymal and non-parenchymal liver cells ex vivo. HBV specific siRNA (si-1.2) or 15 triphosphated 3p-siRNAs 3p-1.2 was complexed with PEl and added into the supernatant of 16 (A) isolated primary human hepatocytes, (B) liver sinusoidal endothelial cells and (C) liver 17 macrophages. Cells were analyzed for IFN- $\beta$ expression relative to GAPDH by real-time 18 RT-PCR 20h after treatment, respectively. Mock treated cells were set to 1. Data are given 19 as mean $\pm \mathrm{SD}, \mathrm{n}=3$. 


\section{A HepG2-H1.3}
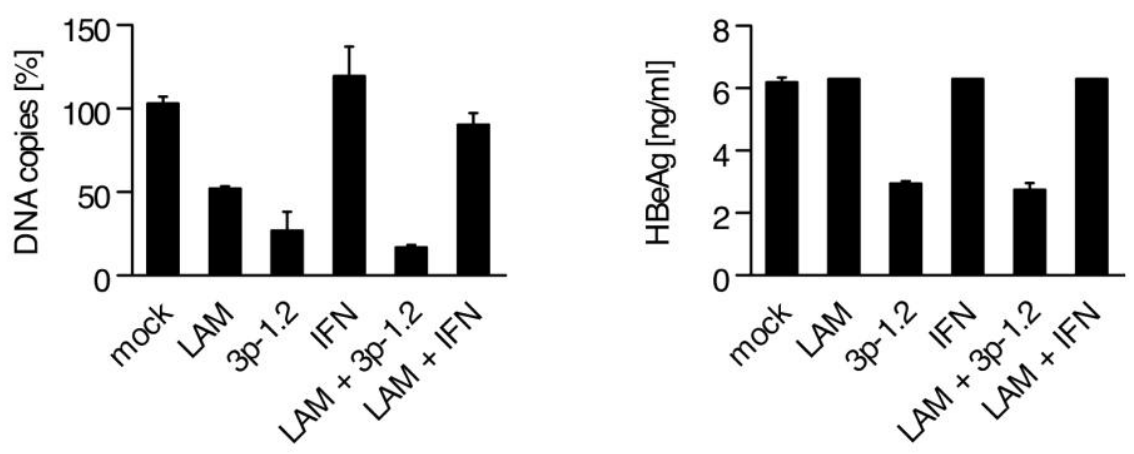

\section{B Primary human hepatocytes}
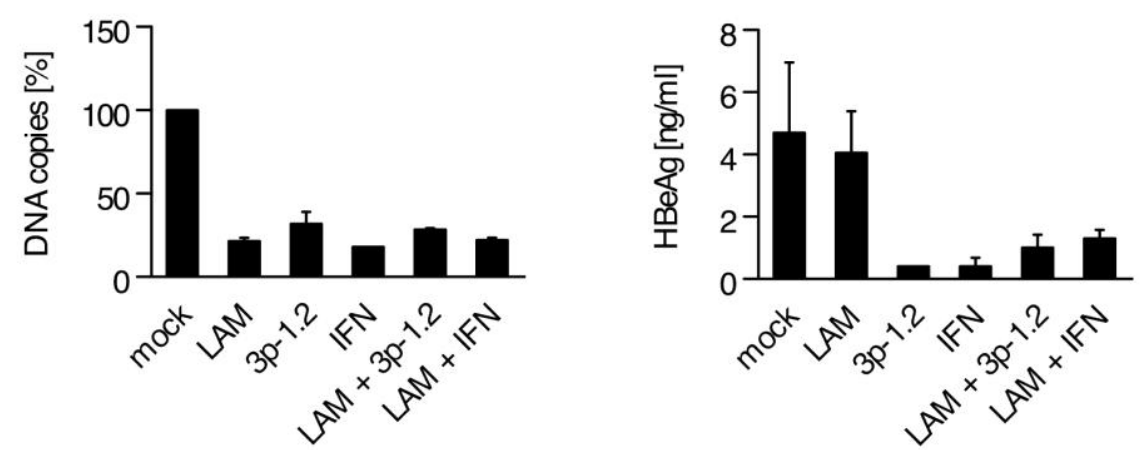

21 Supplementary Figure 3: Antiviral effect of 3p-siRNA compared to exogenous

22 interferon and lamivudine treatment. Hepatoma HepG2-H1.3 cells (A) and primary

23 human hepatocytes (B) were treated with lamivudine (LAM, $0.1 \mu \mathrm{m}$, corresponding to the

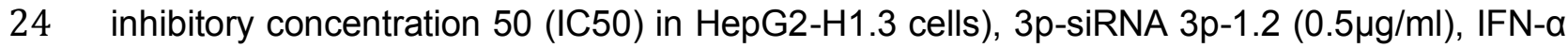

25 (Roferon-A®, Hoffmann-La Roche Ag, Basel, Switzerland; 1000U/ml), a combination of

26 lamivudine and 3p-1.2 or a combination of lamivudine and IFN- $\alpha$. HBV DNA levels (left

27 panels) and $\mathrm{HBeAg}$ (right panels) secreted into the cell culture medium are given. Mean

28 values of DNA copies from mock treated cells were set to $100 \%$. Data are shown as mean $29 \pm \mathrm{SD}, \mathrm{n}=3$. 


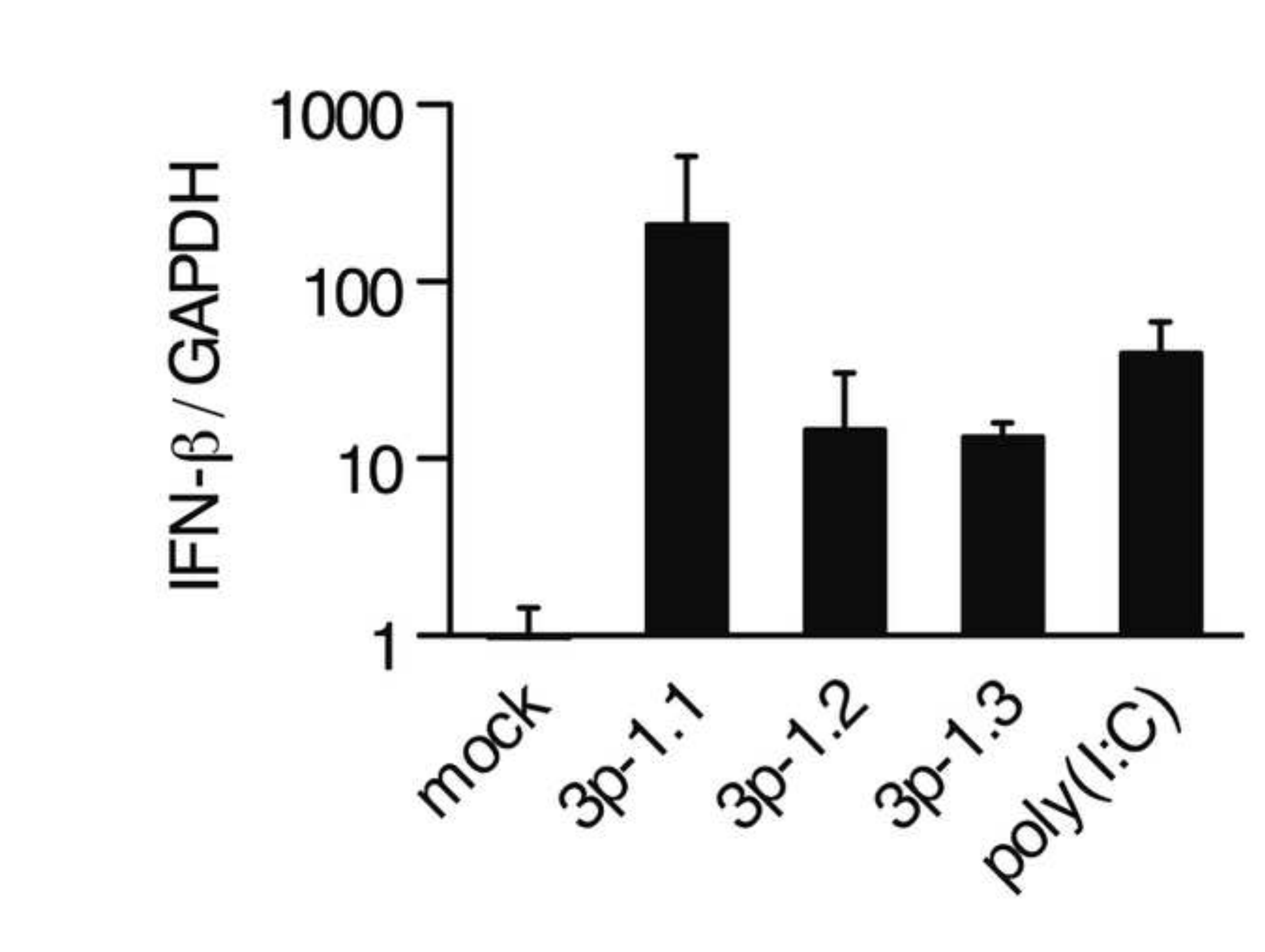

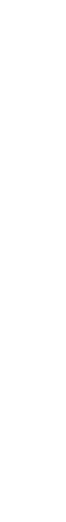

-
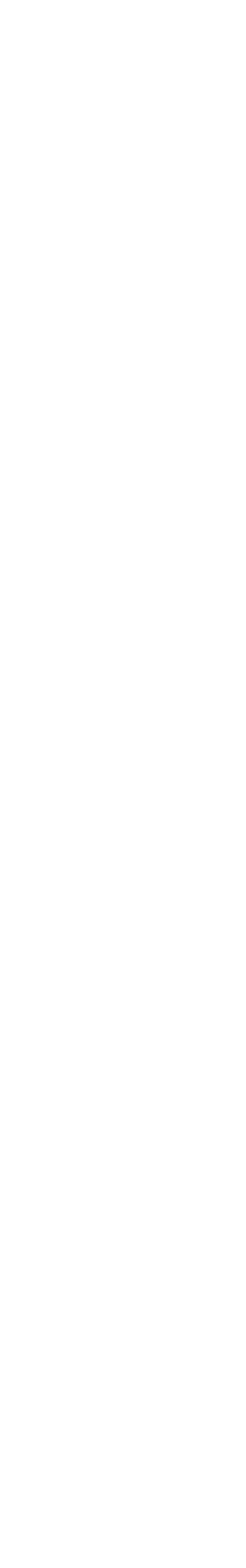

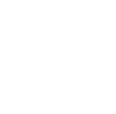

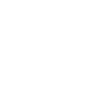

\section{Supplementary Figure}

.

21000 

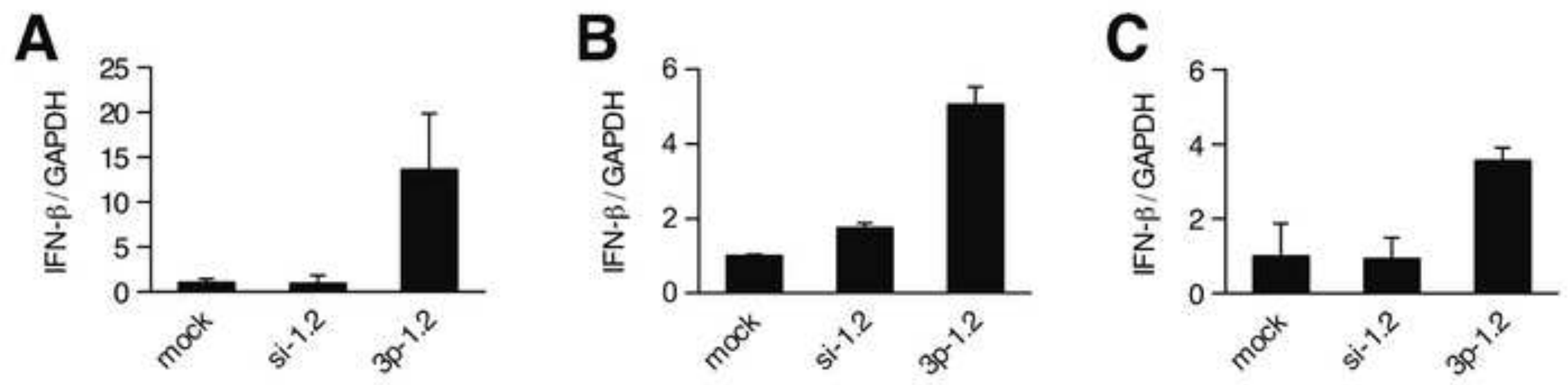
A HepG2-H1.3

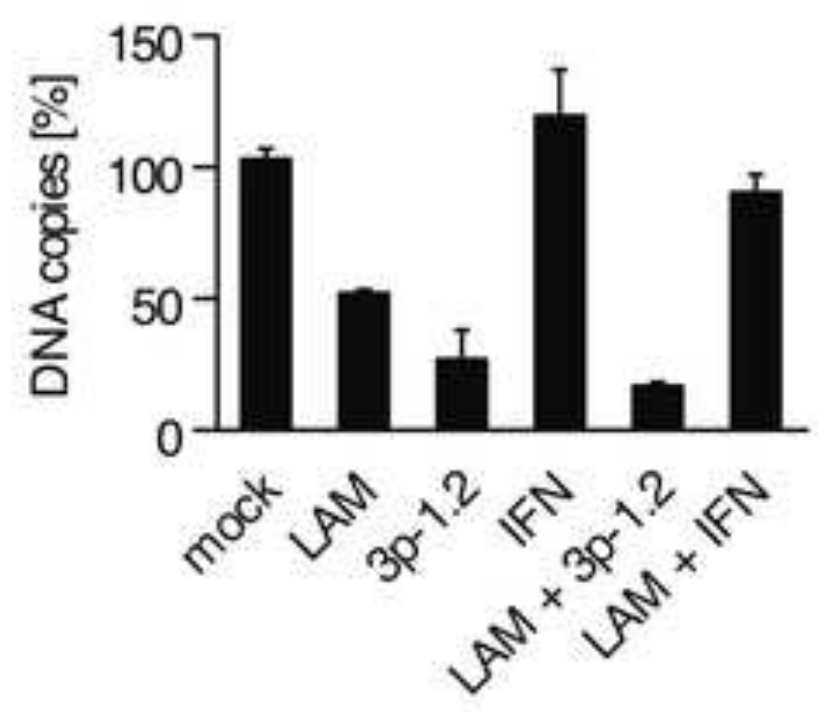

B Primary human hepatocytes

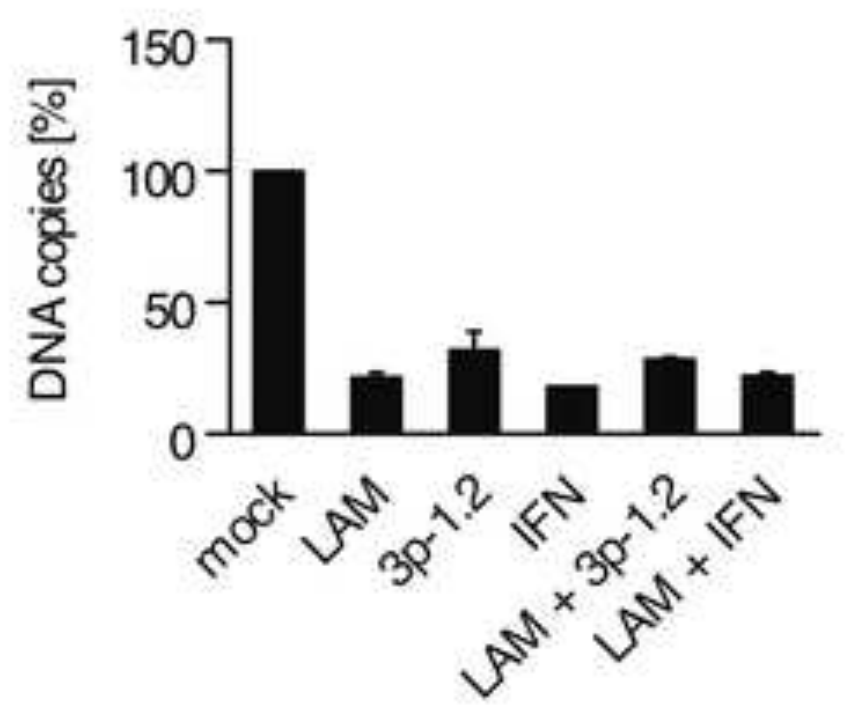

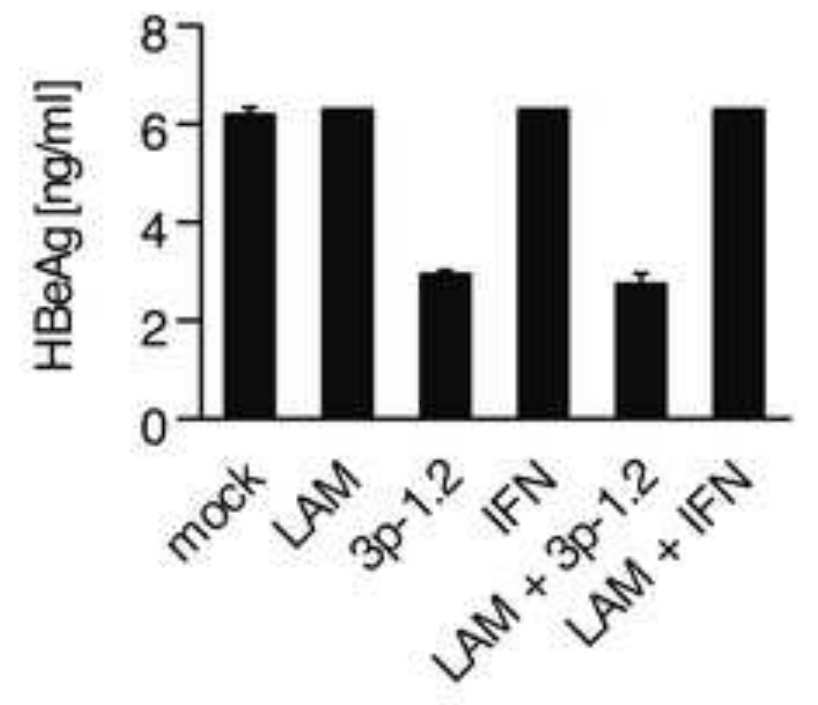

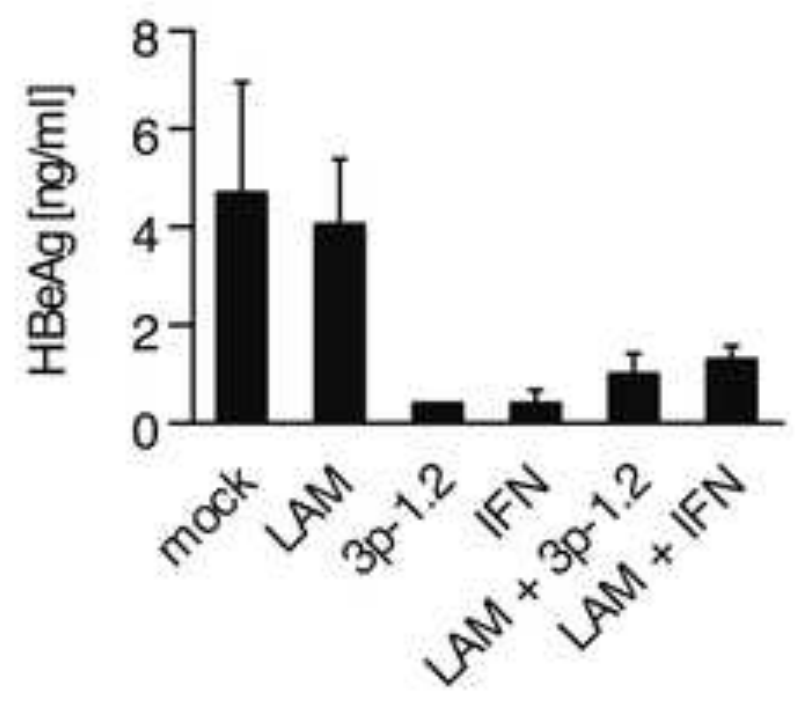

